\title{
Electrochemical sensors based on functionalized carbon nanotubes modified with platinum nanoparticles for the detection of sulfide ions in aqueous media
}

\author{
SOHA MOHAJERI*iD, ABOLGHASSEM DOLATI* and SALVA SALMANI REZAIE \\ Department of Materials Science and Engineering, Sharif University of Technology, Azadi Ave., \\ P.O. Box 11155-9466, Tehran, Iran \\ E-mail: smohajeri@alum.sharif.edu; dolati@sharif.edu
}

MS received 8 January 2019; revised 12 January 2019; accepted 14 January 2019; published online 13 February 2019

\begin{abstract}
Vertically aligned carbon nanotube (CNT) arrays were synthesized by thermal chemical vapor deposition (CVD) on stainless steel substrates coated by cobalt nanoparticles as catalyst. Morphological and elemental analyses conducted by scanning electron microscopy (SEM) and energy dispersive X-ray spectroscopy (EDX) revealed that bamboo-like CNTs were blocked by Co nanoparticles at the tips. The fabricated nanotubes underwent functionalization by electrochemical oxidation in sulfuric acid, and the subsequent structural studies, as well as Fourier transform infrared (FTIR) spectroscopy confirmed that the tips of functionalized CNTs were opened while oxygenated functional groups were generated at the sidewalls and tube endings. In order to enhance the catalytic performance of the functionalized CNT-based electrodes, platinum nanoparticles were deposited on nanotubes by the potentiostatic and pulse potential electrodeposition processes, and the optimum operating parameters in both techniques were determined. The catalytic activities of these two electrodes towards methanol oxidation were determined by cyclic voltammetry (CV) testing, and a superior electrocatalytic activity and poisoning tolerance were detected for the electrode prepared by pulse deposition. The sensing performance of the pulse plated Pt/CNT electrode for the electrochemical detection and oxidation of dissolved sulfide ions was investigated. A sensitivity of $0.632 \mu \mathrm{A} \mu \mathrm{M}^{-1} \mathrm{~cm}^{-2}$ and a detection limit of $0.26 \mu \mathrm{M}$ were obtained, indicating the enhanced capabilities of the developed sensor as a promising candidate for various industrial and environmental applications.
\end{abstract}

Keywords. Functionalized carbon nanotubes; platinum nanoparticles; electrodeposition; methanol oxidation; sulfide sensor.

\section{Introduction}

The unique electrical, thermal, chemical, and mechanical properties of carbon nanotubes (CNTs) have made them intriguing candidates for the development of new electronic devices, chemical/electrochemical sensors and biosensors, transistors, hydrogen storage cells, supercapacitors, and lithium-ion batteries. ${ }^{1-5}$ CNT-based electrodes are extremely promising for low concentration sensing applications due to their large surface area, high electrical conductivity, high strength, and exceptional electrocatalytic activity that account for the extraordinary capabilities of CNTs as high-performance electrochemical sensors. ${ }^{6}$ Chemical vapor deposition (CVD) methods, including microwave plasma enhanced

\footnotetext{
*For correspondence
}

and thermal CVD, are the most extensively used processes for the synthesis of vertically aligned carbon nanotubes since they enable the production of larger quantities of more electrochemically reactive CNTs under easily controllable conditions and at lower costs as compared to other production techniques such as arc discharge and laser ablation. ${ }^{7}$ The synthesis of CNTs by the thermal CVD method involves the decomposition of gaseous carbon precursors at elevated temperatures on the surface of nanosized transition metal catalysts such as nickel, iron, or cobalt. ${ }^{8}$ Despite the high efficiency of the thermal CVD process, the formation of byproducts and impurities such as metal encapsulated nanoparticles at the tips of CNTs is an inevitable drawback that can be extremely detrimental to physicochemical properties of the fabricated nanotubes. ${ }^{9}$ To tackle this issue, the electrochemical oxidation 
technique can be employed to open the closed tips of CNTs and simultaneously produce oxygen-containing functional groups at tube endings and defects along the sidewalls. This approach can significantly alter the electronic and structural properties of nanotubes, expedite the electron transfer kinetics at their surfaces, and make them selective to target analytes, thereby enhancing the performance of CNTs as electrochemical sensors. ${ }^{10}$ Moreover, the modification of functionalized CNTs with nanosized noble metals such as gold, platinum, or palladium can further improve the reactivity of nanotubes towards the electrochemical oxidation of organic compounds such as methanol, and will substantially boost their sensitivity for the detection of a wide range of biomolecules including hydrogen sulfide, DNA, and glucose. ${ }^{11}$ Among various materials reported in the literature, Pt nanoparticles have attracted considerable research attention owing to their remarkable electrocatalytic activity. ${ }^{12}$ Although different methods such as sputtering and electrophoretic deposition have been applied for the synthesis of Pt-modified CNTs, the electrodeposition technique has been proven to offer distinct advantages over alternative approaches due to providing an appropriate control over the size and density of the deposited Pt nanoparticles. ${ }^{13-15}$ However, this technique still has problems related to the non-uniform distribution, agglomeration, and detachment of Pt nanoparticles. Hence, the optimization of the electrodeposition conditions is a matter of great concern in order to facilitate the homogenous dispersion of $\mathrm{Pt}$ nanoparticles on the large surface area of CNTs and effectively develop an electrocatalytic sensing platform. ${ }^{16}$ Nevertheless, no research has so far compared the impacts of the potentiostatic and pulse potential electrodeposition of Pt nanoparticles on the morphological structure and electrocatalytic activity of Pt-modified CNTs. The idea of using CNTbased sensors for the detection and electrochemical oxidation of sulfide ions has been the subject of much interest. ${ }^{17}$ Aqueous hydrogen sulfide solutions play an important role within biogeochemical processes and wastewater treatment technology; however, the uncontrolled release of high concentrations of sulfide can considerably threaten the surrounding ecosystems and endanger human health. ${ }^{18}$ Although few researchers have examined the electrochemical detection of dissolved sulfide by CNT-based sensors, ${ }^{19}$ the influence of the modification of CNTs by Pt nanoparticles on the sensing properties of Pt-modified CNTs for the detection of sulfide ions in aqueous media has been unexplored. In this work, vertically aligned CNT-based electrodes modified with nanosized Pt particles were fabricated for the detection and oxidation of sulfide ions in aqueous media. The objective of this paper was to examine the operating parameters for the electrodeposition of platinum in order to synthesize Pt/CNT electrodes with the optimal electrocatalytic performance and morphological structure. Furthermore, this study aimed to explore the sensitivity of the optimized Pt-modified CNTs towards sulfide ions in aqueous media.

\section{Experimental}

Type 304 stainless steel substrate was etched in a $9 \mathrm{M}$ sulfuric acid solution $\left(\mathrm{H}_{2} \mathrm{SO}_{4} 98 \%\right.$, Merck) for $10 \mathrm{~min}$ so that the protective chromium oxide layer was removed and the surface of the substrate was activated. Afterwards, a thin cobalt layer was electrodeposited as an active catalyst on the substrate from a bath containing double distilled water, $0.25 \mathrm{M} \mathrm{CoSO}_{4} .7 \mathrm{H}_{2} \mathrm{O}, 0.5 \mathrm{M} \mathrm{H}_{3} \mathrm{BO}_{3}$, and $1 \mathrm{M} \mathrm{Na}_{2} \mathrm{SO}_{4}$. All reagents were analytical grade from Merck. The bath temperature was maintained at $25^{\circ} \mathrm{C}$ and the $\mathrm{pH}$ was adjusted to a value of $3.8 \pm 0.2$. Electrodeposition of cobat was conducted using a Metrohm Autolab $302 \mathrm{~N}$ system in a conventional three-electrode cell consisting of $0.5 \mathrm{~cm} \times 0.5 \mathrm{~cm}$ etched stainless steel and $2 \mathrm{~cm} \times 1 \mathrm{~cm}$ platinum plates as working and counter electrodes, respectively, and the potential was recorded with respect to the saturated calomel electrode (SCE). Linear sweep voltammetry (LSV) test was carried out to estimate the potential suited for the deposition of Co nanoparticles, and the potentiostatic technique was applied to deposit the cobalt layer. Synthesis of carbon nanotubes (CNTs) was performed by thermal chemical vapor deposition (CVD) technique, based on the pyrolysis of ethylenediamine. The applied reactor consisted of a tube furnace (Carbolite, STF $15 / 75$ model) and a quartz tube (inner diameter $6 \mathrm{~mm}$, length $110 \mathrm{~cm}$ ). Initially, the tube furnace was heated to $750^{\circ} \mathrm{C}$ and subsequently, the cobalt-coated substrates were placed in the preheated furnace and sintered for 4 min under a flow of $\mathrm{N}_{2}$ gas. Afterwards, $\mathrm{N}_{2}$ was bubbled through the ethylenediamine container and ethylenediamine was introduced into the furnace at a flow rate of $400 \mathrm{~cm}^{3} \mathrm{~min}^{-1}$. Finally, after a reaction time of $30 \mathrm{~min}$, the reactor was naturally cooled to room temperature under $\mathrm{N}_{2}$ protection, and CNTs were fabricated. A TESCAN VEGA II scanning electron microscope (SEM) equipped with an energy dispersive X-ray (EDX) analyzer was utilized to examine the morphology and elemental composition of the synthesized pristine CNTs. Since the CNTs produced by thermal CVD on the cobalt-coated substrates contained metallic particles which blocked the ends of nanotubes, the electrochemical oxidation technique was employed to modify the closed tips of nanotubes and simultaneously functionalize them. All the electrochemical processes were performed in a threeelectrode cell including the CNT-coated specimen as working electrode, a platinum foil as a counter electrode, and an $\mathrm{SCE}$ as a reference. The electrochemical oxidation was carried out in a $0.2 \mathrm{M} \mathrm{H}_{2} \mathrm{SO}_{4}$ solution by cycling the potential 10 times between -1 and $0.1 \mathrm{~V}$ vs. SCE at $50 \mathrm{mV} \mathrm{s}^{-1}$, 
Table 1. Operating parameters for the electrodeposition of Pt nanoparticles on functionalized CNTs by different techniques

\begin{tabular}{lcccc}
\hline Deposition technique & Electrode & Deposition potential (V vs. SCE) & Deposition time $(\mathrm{s})$ & Number of cycles \\
\hline Potentiostatic & $\mathrm{Pt}_{1} / \mathrm{CNT}$ & -0.5 & 100 & \\
& $\mathrm{Pt}_{2} / \mathrm{CNT}$ & -0.6 & 100 & \\
& $\mathrm{Pt}_{3} / \mathrm{CNT}$ & -0.8 & 50 & \\
Pulse Potential & $\mathrm{Pt}_{4} / \mathrm{CNT}$ & -0.6 & $\mathrm{~T}_{\text {on }}=10, \mathrm{~T}_{\text {off }}=100$ & 10 \\
& $\mathrm{Pt}_{5} / \mathrm{CNT}$ & $\mathrm{E}_{\text {on }}=-0.6, \mathrm{E}_{\text {off }}=-0.35$ & $\mathrm{~T}_{\text {on }}=50, \mathrm{~T}_{\text {off }}=10$ & 10 \\
& $\mathrm{Pt}_{6} / \mathrm{CNT}$ & $\mathrm{E}_{\text {on }}=-0.6, \mathrm{E}_{\text {off }}=-0.35$ & $\mathrm{~T}_{\text {on }}=100, \mathrm{~T}_{\text {off }}=10$ & 10 \\
\hline
\end{tabular}

and the surface morphology of the oxidized CNT- based electrode was monitored by SEM. Fourier transform infrared (FTIR) spectroscopy was used to ensure the formation of functional groups on the surface of CNTs after oxidation. The FTIR spectrum was recorded on a Shimadzu IRAffinity1 spectrophotometer, controlled by a PC running IR solution software that accompanied the equipment. Approximately 1 mgr of oxidized CNTs was picked up from the surface of the electrode and was well mixed into $400 \mathrm{mgr}$ potassium bromide, and the obtained powder was pressurized to convert to a thin and transparent pellet. Finally, transmittance spectrum of infrared beams was collected in the range 400$4000 \mathrm{~cm}^{-1}$ and the functional groups were identified. To further enhance the catalytic property of the functionalized CNT electrode, potentiostatic and pulse potential deposition techniques were utilized to modify the functionalized CNTs with platinum nanoparticles. The aqueous electrolyte ( $\mathrm{pH} 0.6$ ) was composed of $1 \mathrm{mM} \mathrm{H}_{2} \mathrm{PtCl}_{6} \cdot 6 \mathrm{H}_{2} \mathrm{O}$ ( $\sim 40 \% \mathrm{Pt}$, Merck) and $0.5 \mathrm{M} \mathrm{H}_{2} \mathrm{SO}_{4}$ (98\%, Merck), with a functionalized CNT working electrode, a platinum wire counter electrode, and an SCE. The electroplating bath was purged with $\mathrm{N}_{2}$ at room temperature for $10 \mathrm{~min}$ prior to the deposition of platinum and the operating parameters are summarized in Table 1. Pt nanoparticles were also deposited on unfunctionalized (pristine) CNT electrode for comparison. The surface morphologies of Pt-modified CNTs were studied by SEM, and the optimal operating parameters were determined.

The electrocatalytic activities of the optimal electrodes prepared by the potentiostatic and pulse potential deposition techniques towards methanol oxidation were investigated. Prior to the methanol oxidation analyses, the selected electrodes were activated by cyclic voltammetry (CV) in an $\mathrm{N}_{2}$ saturated $0.5 \mathrm{M} \mathrm{H}_{2} \mathrm{SO}_{4}$ aqueous solution and surface contaminations were eliminated. In this regard, a cyclic potential range of -0.2 to $1.0 \mathrm{~V}$ vs. SCE at a scan rate of $50 \mathrm{mV} \mathrm{s}^{-1}$ was selected to avoid probable alteration of Pt structure that might take place outside this potential range. Afterwards, the electrochemical oxidation of methanol on the surfaces of optimal Pt/CNT electrodes was examined in a mixed solution containing $0.5 \mathrm{M} \mathrm{H}_{2} \mathrm{SO}_{4}$ and $1.0 \mathrm{M}$ methanol, and the voltammetric curves were recorded between -0.2 and $1.0 \mathrm{~V}$ vs. SCE at a sweep rate of $50 \mathrm{mV} \mathrm{s}^{-1}$. The sensing properties of the fabricated electrodes were assessed as electrochemical sensors towards the detection of sulfide ions. Electrochemical experiments were carried out via an EG\&G PAR potentiostat model 273A, with a conventional three-electrode system, including the pulse plated Pt/CNT electrode as the working electrode, a platinum wire (1 $\mathrm{mm}$ diameter) as the counter electrode, and an SCE as a reference. The electrolyte contained different concentrations of sodium sulfide nonahydrate (Sigma-Aldrich, UK), 3.5\% NaCl (Merck, Germany), and distilled water, with an adjusted $\mathrm{pH}$ of 6.8 at $25^{\circ} \mathrm{C}$. Differential pulse voltammetry (DPV) and CV measurements were recorded from -1 to $1 \mathrm{~V}$ under different conditions of sulfide ion concentrations $(0-4 \mathrm{Mm})$ and scan rates $\left(40-100 \mathrm{mV} \mathrm{s}^{-1}\right)$ to determine the electrochemical sensitivity of the electrode and identify the mechanism of the oxidation of sulfide ions. A comparison of the Differential Pulse Voltammetry (DPV) and CV techniques was performed, and the most efficient technique for obtaining the highest sensitivity towards sulfide ions was determined. The electrochemical impedance spectroscopy (EIS) measurements were performed to investigate the oxidation behavior of the designed sensor towards different sulfide ion concentrations. The testing equipment was an Autolab PGSTAT $302 \mathrm{~N}$ system, and a conventional threeelectrode cell including the pulse plated Pt/CNT specimen as the working electrode, an SCE as a reference, and a platinum plate as the counter electrode was employed. The EIS tests were conducted at a frequency range of $100 \mathrm{kHz}$ to $0.05 \mathrm{~Hz}$ at a potential of $0.25 \mathrm{~V}$ with an $\mathrm{AC}$ excitation amplitude of $10 \mathrm{mV}$. Amperometric current-time response curves were also recorded to study the detective performance of the sensor while a magnetic stirrer provided the convective transport during the amperometric measurements. A transmission electron microscope (TEM, EM-10C Model) was used to explore the unzipping of the pulse plated Pt/CNT electrode after the sulfide oxidation process.

\section{Results and Discussion}

\subsection{Electrodeposition of catalyst nanoparticles and morphological study of CNTs}

In order to determine the optimal potential for the deposition of cobalt on the stainless steel substrate prior to the growth of CNTs, the LSV curve was plotted in the range of 0 to $-1.7 \mathrm{~V}$ at a scan rate of $50 \mathrm{mV} \mathrm{s}^{-1}$. As depicted in Figure 1, there is a cathodic peak at $-1.1 \mathrm{~V}$, corresponding to cobalt deposition. At more negative 


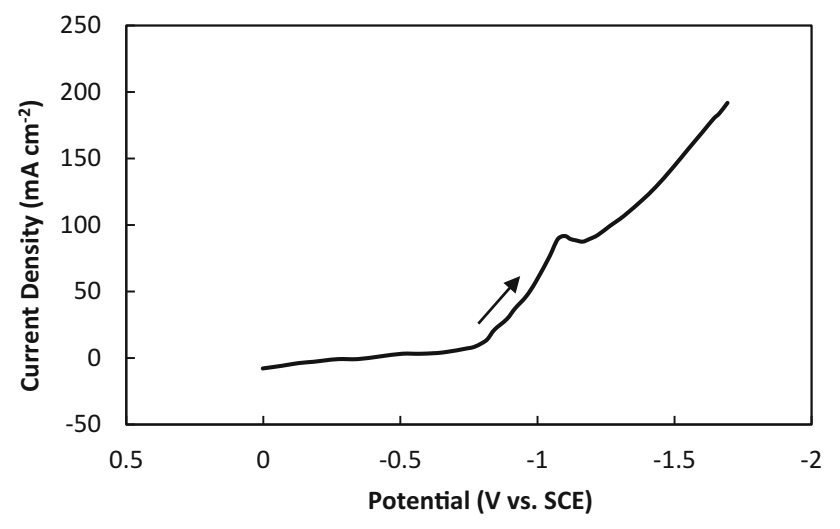

Figure 1. Linear sweep voltammetry curve for the electrodeposition of cobalt on stainless steel substrate prior to the growth of CNTs at a scan rate of $50 \mathrm{mV} \mathrm{s}^{-1}$.

potential values, the current density increases rapidly and the evolution of hydrogen hinders the metal deposition. Hence, the potential of $-1.1 \mathrm{~V}$ was selected as the optimum deposition potential and it was applied for $5 \mathrm{~s}$ to deposit a thin cobalt film on the substrate.

Pristine CNTs were synthesized on the cobalt layer, and the structure and morphological features of the obtained nanotubes were analyzed by SEM. According to Figure 2a, the uniform diameter of CNTs varies in the range of $150-200 \mathrm{~nm}$, and as the sintered cobalt layer is dense enough for catalyzing the growth of nanotubes, high-density CNTs are produced. The local bending of the CNTs tips can be observed and virtually all of the tubes are closed at both ends. Figure $2 b$ indicates that due to the high density of cobalt nanoparticles and the Van der Waals forces between the tubes, CNT arrays are vertically aligned and keep a relatively homogeneous distribution. This figure reveals the bamboo-like structure of nanotubes, and this type of structure is typically generated when nitrogen-containing chemicals such as ethylenediamine are used as the precursor for the fabrication of CNTs by the CVD process. ${ }^{20}$ Additionally, the presence of nitrogen gas provides a favorable condition for the formation of bamboo-like CNTs. The role of nitrogen is to keep the surface of the thin cobalt layer active and clean during the pretreatment of catalyst nanoparticles and perhaps at the initial stage of the CNTs growth. Moreover, nitrogen enhances the bulk diffusion of carbon into the catalyst nanoparticles, leading to the formation of bamboo-shaped nanotubes. ${ }^{21}$ Figure $2 \mathrm{c}$ displays the top view SEM image of nanotubes with close ends at high magnification. To gain a detailed insight into the chemical properties of CNTs, point A on the tip of a nanotube in Figure $2 \mathrm{c}$ was characterized by EDX analysis. The chemical composition of point A represents that the tip of the examined CNT is chiefly composed of carbon, showing that the growth of the tube occurs from its closed-end tip. The existence of cobalt at the end of the CNT indicates that a tip-growth mechanism occurs where the catalyst nanoparticles are detached from the surface during the CNT growth. It should be noted that during the initial stage of the nanotubes nucleation, the precursor is decomposed and carbon atoms diffuse into the catalyst particles, leading to the formation of a carbon cap around cobalt particles. In the growth process, the caps created on the carbon-coated particles lift off and further carbon atoms constantly join the edges of the caps, developing tubes which grow away from the particles. These tubes contain small amounts of cobalt particles that are separated from the surface and move towards the tips of CNTs. ${ }^{9}$

\subsection{Electrochemical functionalization of CNTs}

The electrochemical oxidation technique was employed to open the closed tips of pristine CNTs and simultaneously functionalize them so that the electrochemical performance of nanotubes could be enhanced. Figure 3 demonstrates the $\mathrm{CV}$ curves of the CNT-based electrode recorded in a $0.2 \mathrm{M} \mathrm{H}_{2} \mathrm{SO}_{4}$ solution by cycling the potential from -1 to $0.1 \mathrm{~V}$ at $50 \mathrm{mV} \mathrm{s}^{-1}$. In order to accurately detect the changing behavior of nanotubes in different cycles, the CVs were plotted in the 1st, 5th, and 10th cycles. The first scan of the potential does not exhibit a well-defined oxidation peak, while after the 5th and 10th scans wide oxidation peaks are observed between $-0.4 \mathrm{~V}$ (i.e., open circuit potential) and $0.1 \mathrm{~V}$, indicative of the electrochemical oxidation of the CNTs. It has been reported that CNT purification by oxidation in the sulfuric acid solution yields the formation of oxygenated functional groups (predominantly carboxylic acid) at the sidewalls and tube endings. ${ }^{22}$ As depicted in Figure 3 , the peaks shift toward more negative potentials and higher current densities in successive cycles. This can be attributed to the formation of functional groups during the prior cycle which significantly enhances the electrochemical reactivity of nanotubes, leading to the acceleration and intensification of oxidation in the proceeding cycle.

Figures $4 \mathrm{a}$ and $4 \mathrm{~b}$ illustrate the morphological characteristics of CNT arrays after the 1st and 10th cycles of electrochemical oxidation in $0.2 \mathrm{M} \mathrm{H}_{2} \mathrm{SO}_{4}$, respectively. It is evident that the electrochemical oxidation cuts CNTs in smaller segments substantially decreases the dimeter of nanotubes, and removes metal catalysts resulting in open-ended CNTs. Moreover, the electrochemical purification usually increases the concentration of sidewall defects and improves the 


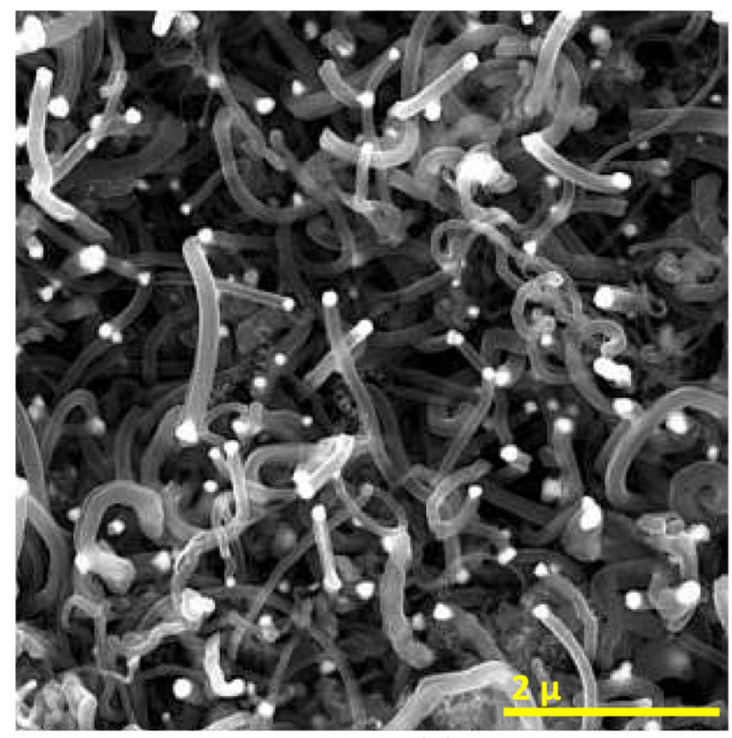

(a)

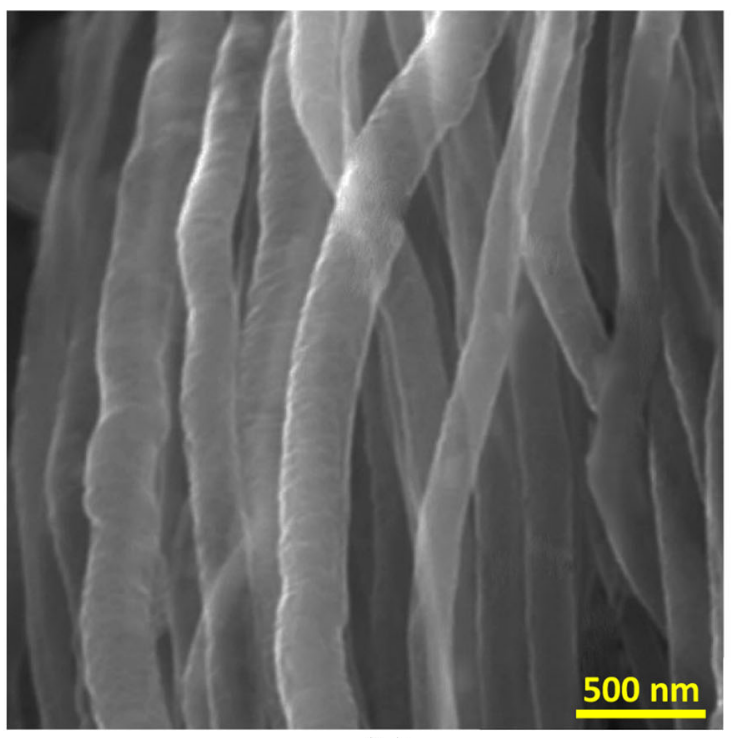

(b)

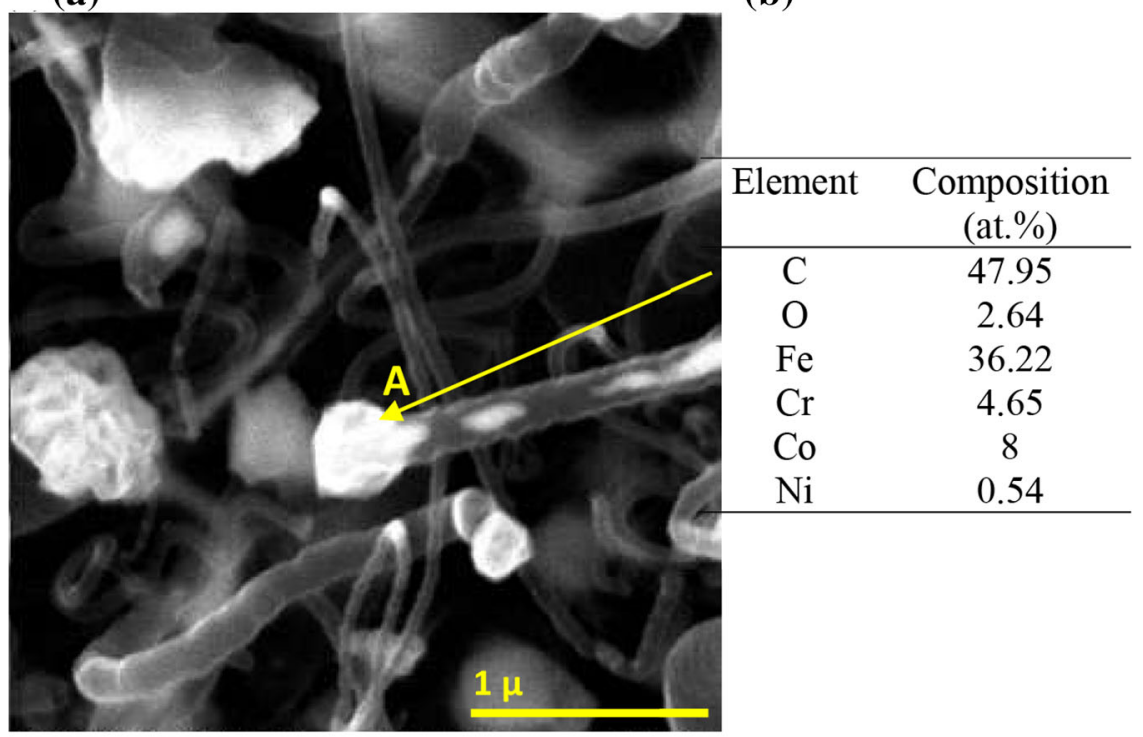

(c)

Figure 2. SEM images of (a) Low magnification top view; (b) high magnification side view; (c) high magnification top view of vertically aligned pristine CNT arrays. EDX elemental analysis was performed on a nanotube tip.

surface reactivity; therefore, it is favorable for the functionalization of un-capped CNTs. ${ }^{10}$

In order to investigate the influence of electrochemical oxidation on the formation of functional groups on the surface of CNTs, nanotubes were characterized by FTIR. Figure 5 shows the transmittance infrared spectrum of the CNT electrode after 10 oxidation cycles in a $0.2 \mathrm{M} \mathrm{H}_{2} \mathrm{SO}_{4}$ solution. The wide peak at $3427 \mathrm{~cm}^{-1}$ and other smaller peaks at $2910 \mathrm{~cm}^{-1}$ and $2360 \mathrm{~cm}^{-1}$ refer to the $\mathrm{O}-\mathrm{H}$ stretch of the hydroxyl group. Besides, two peaks appear at 1270 and $1170 \mathrm{~cm}^{-1}$ which are assigned to $\mathrm{C}-\mathrm{O}$ bonding, while the peaks at 1630 and $1400 \mathrm{~cm}^{-1}$ can be associated to the $\mathrm{C}=\mathrm{O}$ and $\mathrm{C}-\mathrm{C}$ stretching of the CNTs, respectively. ${ }^{23}$ The FTIR spectrum obviously confirms that the main functional group produced on the surface of CNTs is the carboxyl group $(\mathrm{COOH})$ consisting of a carbonyl group $(\mathrm{C}=\mathrm{O})$ with a hydroxyl group $(\mathrm{O}-\mathrm{H})$ attached to the same carbon atom. The $\mathrm{COOH}$ groups are formed due to the slight oxidation of the surface of nanotubes during the electrochemical process and are successfully attached to the surface of CNTs. It is worth mentioning that functional groups produced on the walls of CNTs along with defects introduced by the oxidation of tubes significantly improve the electrochemical performance of the CNT electrode by altering its electrical structure, increasing its wettability, and expediting the electron transfer kinetics at the surface of the electrode. ${ }^{24}$ 


\subsection{Electrodeposition of Pt nanoparticles on functionalized CNTs}

In order to enhance the catalytic performance of the functionalized CNT electrode as an electrochemical sensor, Pt catalyst nanoparticles were deposited on CNTs by the potentiostatic and pulse potential electrodeposition techniques, and a comparative analysis of these two methods was conducted.

3.3a Potentiostatic electrodeposition: Initially, to investigate the influence of surface functionalization of CNTs on the electrodeposition of platinum, Pt nanoparticles were deposited on pristine and functionalized (10

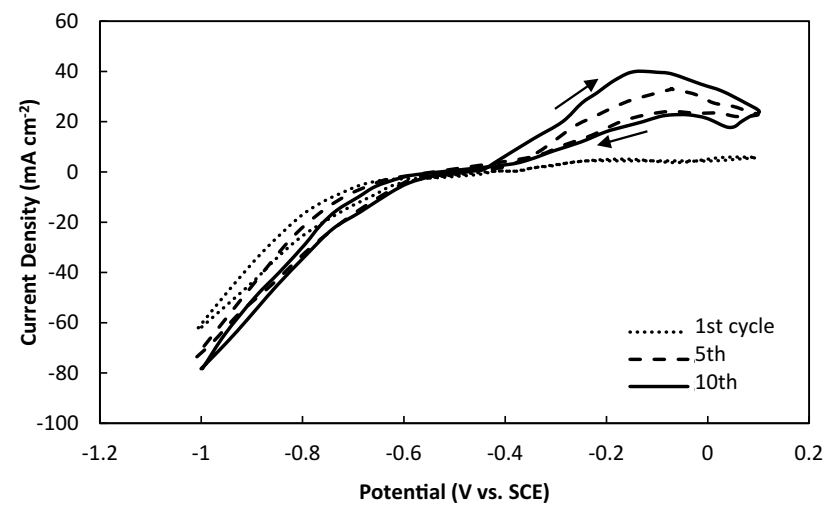

Figure 3. Electrochemical oxidation of the CNTs in $0.2 \mathrm{M}$ $\mathrm{H}_{2} \mathrm{SO}_{4}$ by potential cycling between -1 and $0.1 \mathrm{~V}$ vs. SCE at $50 \mathrm{mV} \mathrm{s}^{-1}$. For more clarity, only the $1 \mathrm{st}, 5$ th, and 10 th $\mathrm{CV}$ curves are displayed.

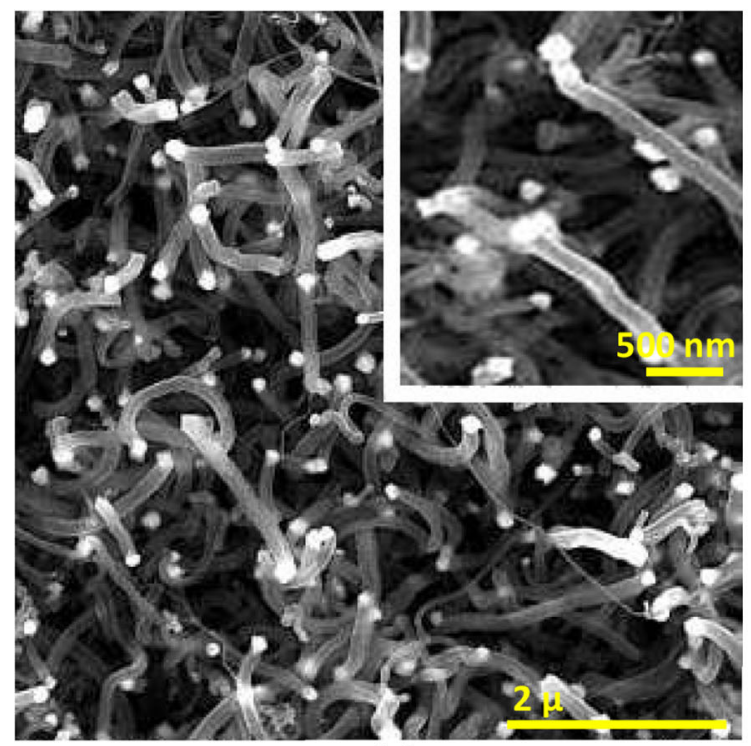

(a) cycles oxidized) CNTs by the potentiostatic technique. The selected potential and time for the deposition of Pt nanoparticles were $-0.6 \mathrm{~V}$ and $100 \mathrm{~s}$, respectively $\left(\mathrm{Pt}_{2} / \mathrm{CNT}\right.$ electrode in Table 1). The surface morphologies of $\mathrm{Pt}_{2} /$ pristine $\mathrm{CNT}$ and $\mathrm{Pt}_{2} /$ functionalized $\mathrm{CNT}$ electrodes are demonstrated in Figure 6. During the electrochemical deposition of platinum on CNTs, nanotubes act as deposition platforms and enable the electrical attachment of Pt nanoparticles without reacting with the metal salt solution. ${ }^{25}$ However, as depicted in Figure $6 \mathrm{a}$ for the pristine CNT electrode, the neutral surface of CNTs does not support the attachment of metallic particles. In this case, only the surface defects, rather than the entire surface of CNTs, serve as active nucleation sites and yield a non-uniform distribution of Pt nanoparticles. As the deposition proceeds, previously deposited

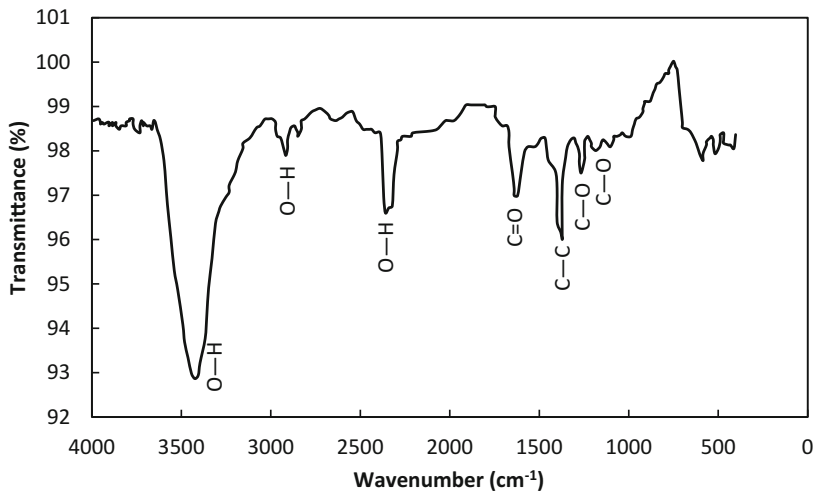

Figure 5. FTIR spectrum for functionalized CNTs after10 oxidation cycles in $0.2 \mathrm{M} \mathrm{H}_{2} \mathrm{SO}_{4}$.

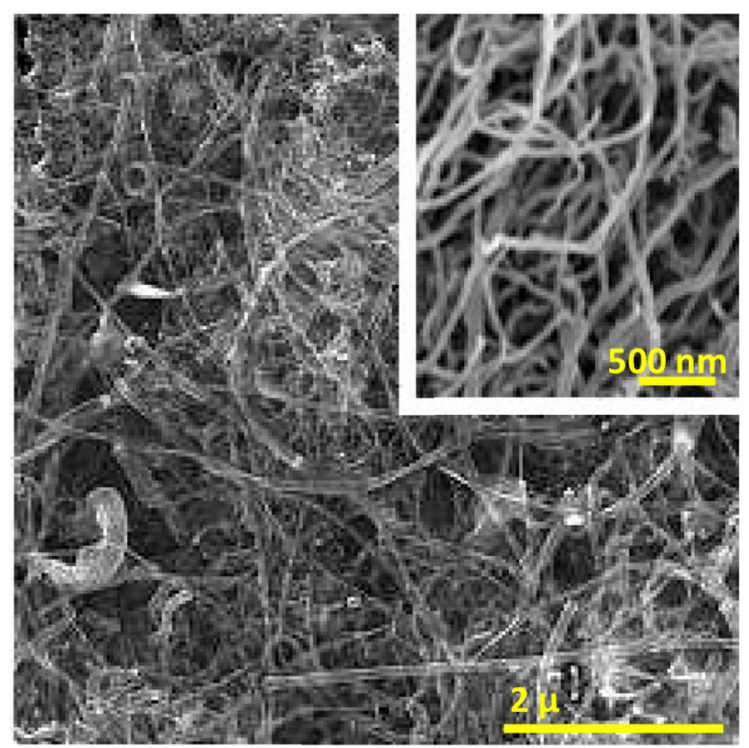

(b)

Figure 4. Top-view SEM images of functionalized CNT arrays after the (a) 1st and (b) 10th cycles of electrochemical oxidation in $0.2 \mathrm{M} \mathrm{H}_{2} \mathrm{SO}_{4}$. The corresponding insets are at the higher magnifications. 


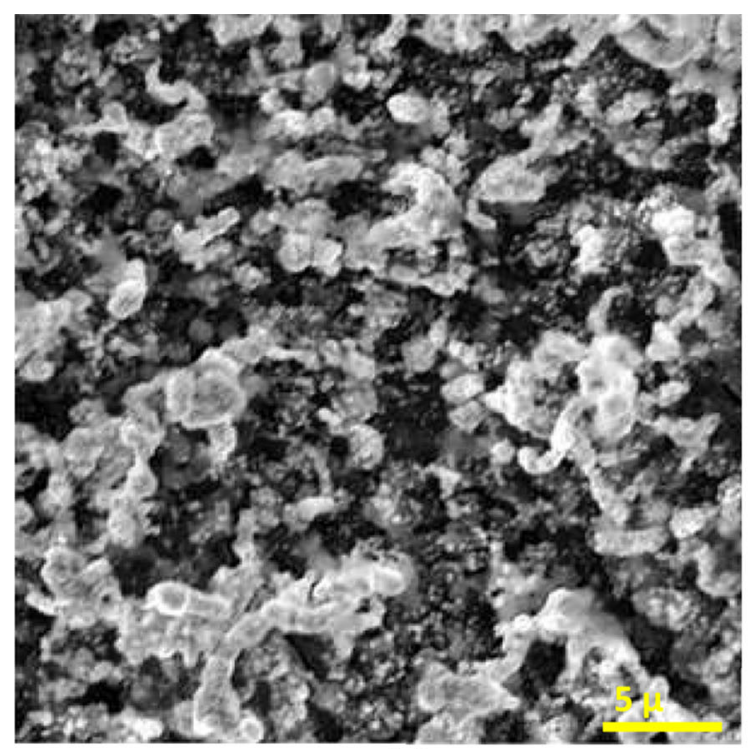

(a)

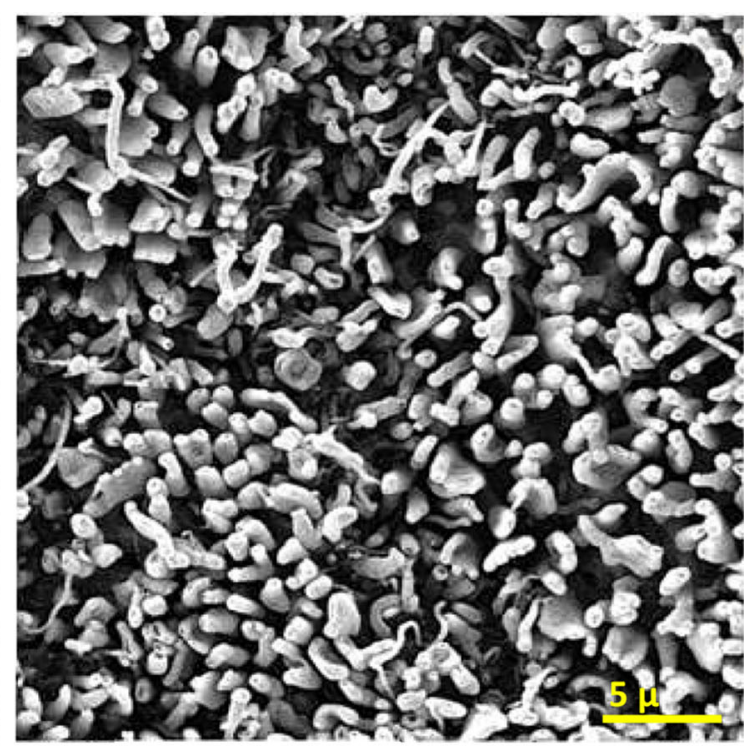

(b)

Figure 6. SEM images of $\mathbf{a} \mathrm{Pt}_{2} /$ pristine CNTs and $\mathbf{b} \mathrm{Pt}_{2} /$ functionalized CNTs.

particles also get involved as nucleation sites and therefore, some agglomerated particles are separately formed on the surface of nanotubes. However, according to Figure 6b, Pt nanoparticles uniformly deposit on the walls of functionalized CNTs, and a homogeneous distribution of Pt nanoparticles is obtained. This uniform morphology can be attributed to the oxygen-containing functional groups which are generated on nanotubes during the electrochemical oxidation process. ${ }^{26}$ These functional groups act as ligands with a strong affinity for metal ions and assist the attachment of Pt nanoparticles on the external surfaces of CNTs. In other words, carboxylic groups which are available on the outer walls of functionalized CNTs are beneficial to obtain a uniform distribution of $\mathrm{Pt}$ nanoparticles by providing more nucleation centers which facilitate the deposition and stabilization of platinum.

In order to examine the influence of various deposition potentials on the surface morphology of Pt-modified CNTs and to study the size and distribution of $\mathrm{Pt}$ nanoparticles, the deposition of $\mathrm{Pt}$ on functionalized CNTs was carried out at $-0.5,-0.6$, and $-0.8 \mathrm{~V}$ for $100 \mathrm{~s}$. Figure 7 displays the SEM images of $\mathrm{Pt}_{1} / \mathrm{CNT}$, $\mathrm{Pt}_{2} / \mathrm{CNT}$, and $\mathrm{Pt}_{3} / \mathrm{CNT}$ electrodes at two different magnifications. According to Figure 7a, it can be observed that $\mathrm{Pt}_{1}$ nanoparticles are not distributed uniformly, and highly agglomerated particles are created on the surface of CNTs. At the reduction potential of $-0.5 \mathrm{~V}$, the driving force for nucleation is inadequate to overcome the activation energy; therefore, particles growth predominates over nucleation, and a smaller number of larger platinum particles is obtained. Moreover, at a low deposition potential, there are relatively few nucleation sites available on the surface of CNTs and thus, $\mathrm{Pt}_{1}$ ions nucleate on the preceding $\mathrm{Pt}_{1}$ clusters rather than on the new sites of CNTs, thereby inducing the agglomeration of flower-like platinum clusters in some regions. Figure $7 \mathrm{~b}$ depicts the SEM image at a higher magnification, and as the crystal growth tends to be the dominant mechanism during the crystallization of platinum, the size of $\mathrm{Pt}_{1}$ nanoparticles varies between approximately 100 and $150 \mathrm{~nm}$. Figures 7c and 7d depict SEM images of $\mathrm{Pt}_{2} / \mathrm{CNT}$ electrode, and it is evident that at a more negative potential the nucleation and deposition of $\mathrm{Pt}_{2}$ nanoparticles mainly occur on the sidewalls of CNTs. As the driving force for the nucleation of $\mathrm{Pt}_{2}$ nanoparticles increases at the deposition potential of $-0.6 \mathrm{~V}$, the number of nucleation sites uniformly increases on the entire surface of nanotubes and consequently, the deposition of a large number of small platinum particles is facilitated. In this case, the size of the deposited $\mathrm{Pt}_{2}$ nanoparticles are smaller than that of $\mathrm{Pt}_{1}$ nanoparticles, and it is measured to be about $70 \mathrm{~nm}$. Figures $7 \mathrm{e}$ and $7 \mathrm{f}$ show the morphological structure of CNTs after the deposition of $\mathrm{Pt}_{3}$ nanoparticles, and it can be observed that under the deposition potential of $-0.8 \mathrm{~V}$, the structure of CNTs are slightly disordered and randomly oriented $\mathrm{Pt}_{3}$ particles are noticeable on the surface of nanotubes. It has been confirmed that if platinum is electrodeposited under highly negative potentials, the evolution of hydrogen in the acidic electrodeposition bath will reduce the cathode efficiency and disturb the deposition. ${ }^{27}$ Thus, the intensive evolution of hydrogen gas around the cathode at the deposition potential of $-0.8 \mathrm{~V}$ accounts for 


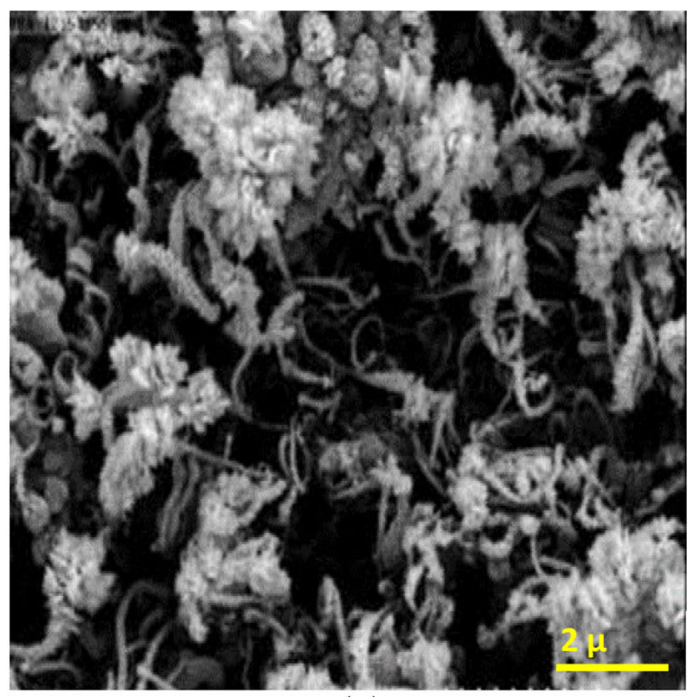

(a)

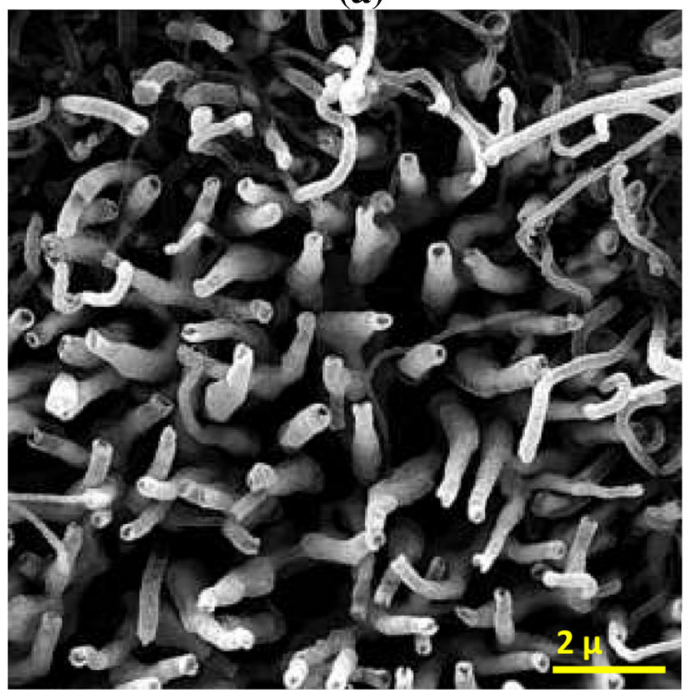

(c)

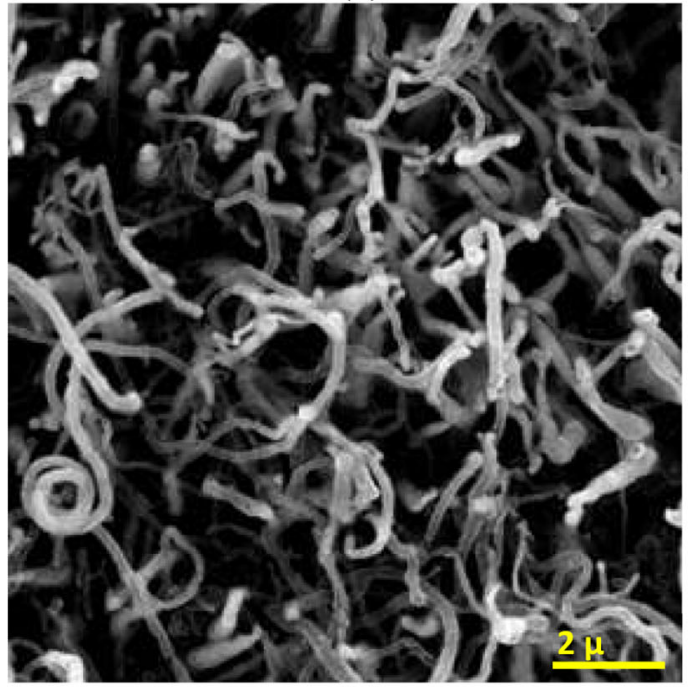

(e)

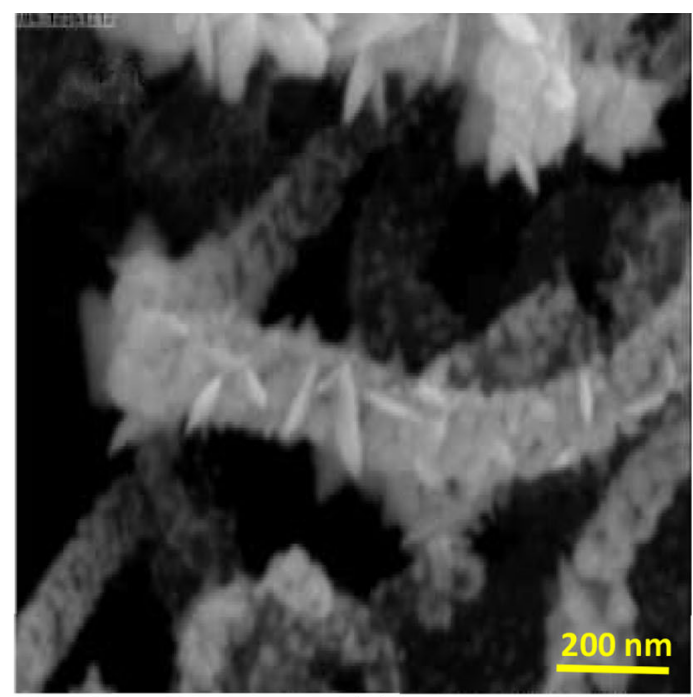

(b)

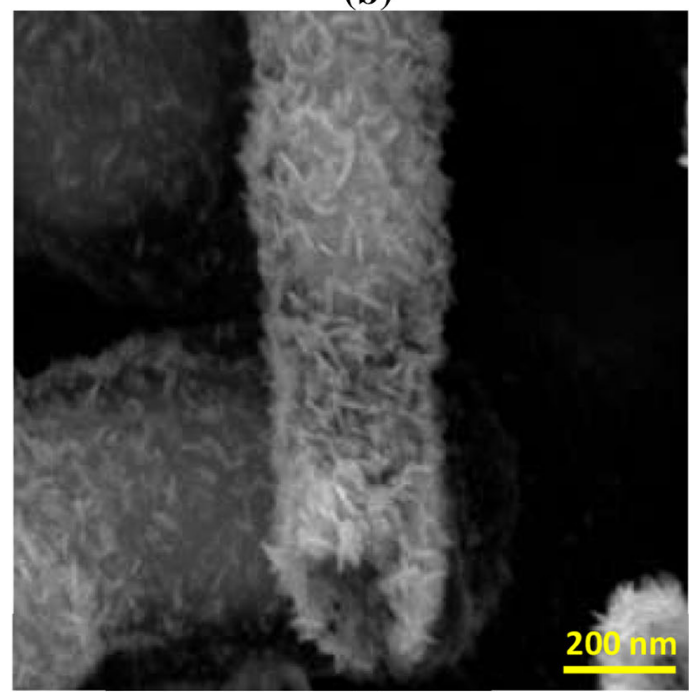

(d)

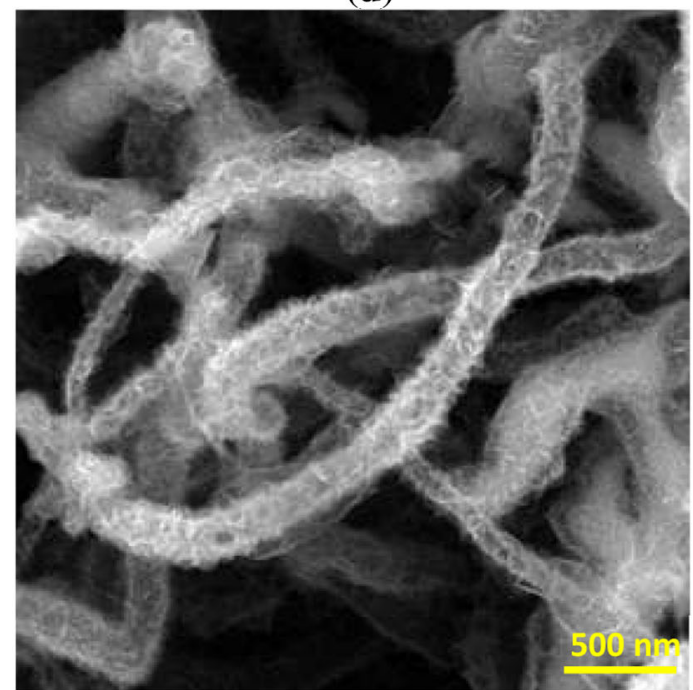

(f)

Figure 7. SEM images of functionalized CNTs after the potentiostatic deposition of Pt nanoparticles for $100 \mathrm{~s}$; (a), (b) $\mathrm{Pt}_{1} / \mathrm{CNT}(\mathrm{E}=-0.5 \mathrm{~V})$; (c), (d) $\mathrm{Pt}_{2} / \mathrm{CNT}(\mathrm{E}=-0.6 \mathrm{~V})$; (e), (f) $\mathrm{Pt}_{3} / \mathrm{CNT}$ $(\mathrm{E}=-0.8 \mathrm{~V})$. 


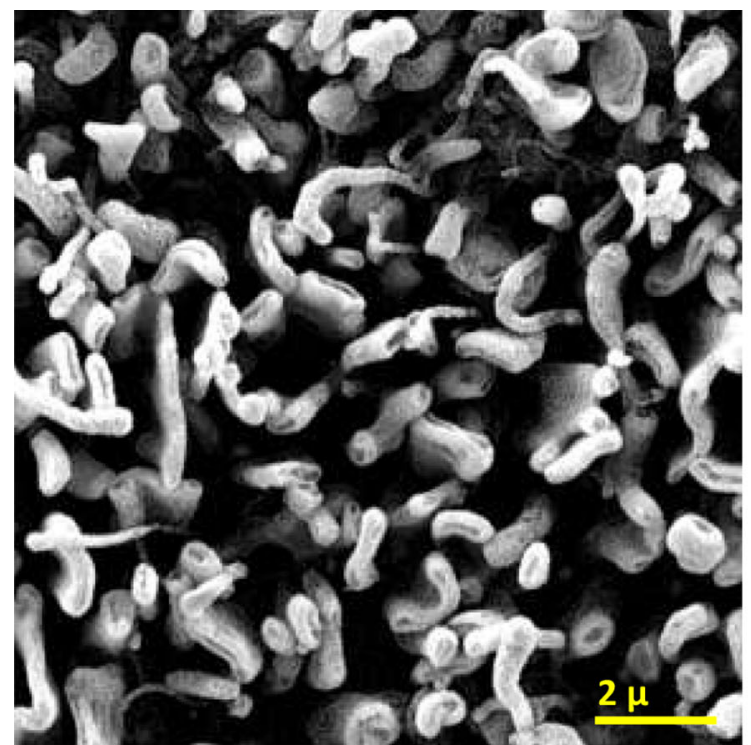

(a)

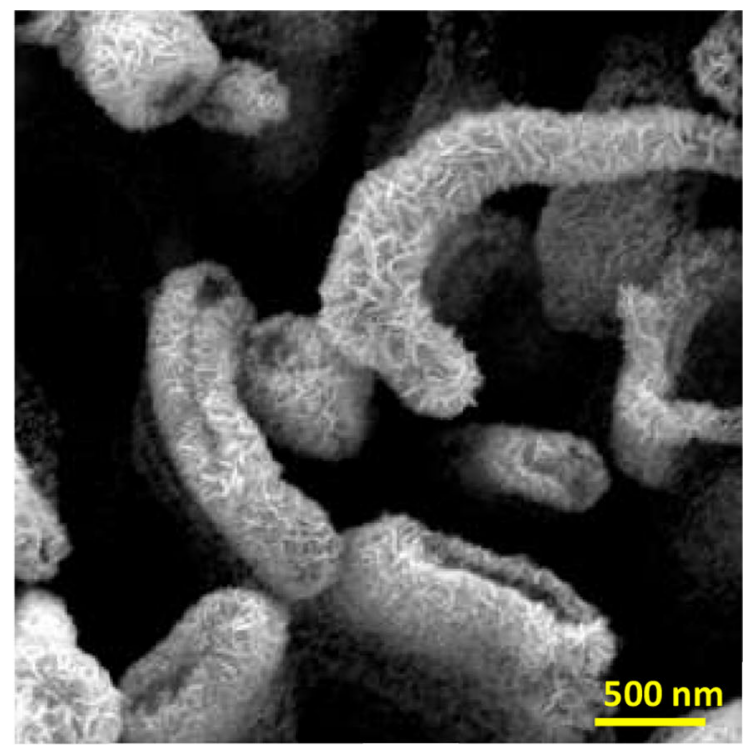

(b)

Figure 8. (a) Low magnification and (b) high magnification $\mathrm{SEM}$ images of $\mathrm{Pt}_{4} / \mathrm{CNT}$ electrode $(\mathrm{E}=-0.6 \mathrm{~V}, \mathrm{t}=50 \mathrm{~s})$.

the disordered CNTs and $\mathrm{Pt}_{3}$ nanoparticles. It should be noted that the crystallization of nanoparticles starts with the nucleation of $\mathrm{Pt}_{3}$ crystals on the active sites of CNTs followed by crystals growth. However, the excessive growth of particles does not occur as the hydrogen evolution reaction subsequently takes place and interrupts the further growth of particles, promoting the formation of particles with the average size of $30 \mathrm{~nm}$.

Based on the above analysis, $\mathrm{Pt}_{2} / \mathrm{CNT}$ electrode exhibits the optimal structure and thus, the deposition potential of $-0.6 \mathrm{~V}$ was selected to study the influence of altering the deposition time on the morphology of platinum nanoparticles. Figure 8 represents the SEM images of $\mathrm{Pt}_{4} / \mathrm{CNT}$ electrode for which platinum nanoparticles were deposited under the reduction potential of $-0.6 \mathrm{~V}$ for $50 \mathrm{~s}$. Comparing Figures $7 \mathrm{c}$ with $8 \mathrm{a}$, it can be observed that over a prolonged deposition time, $\mathrm{Pt}_{2}$ nanoparticles grow cylindrically on the peripheral surface of CNTs, whereas during a shorter deposition time, the deposition of $\mathrm{Pt}_{4}$ nanoparticles mainly occurs at CNTs tips and this triggers the agglomeration of nanotubes tips in some regions. Furthermore, a comparison of Figures $7 \mathrm{~d}$ with $8 \mathrm{~b}$ reveals that for a given deposition potential, if the deposition time is shortened from 100 to $50 \mathrm{~s}$, the size of Pt nanoparticles does not vary and is about $70 \mathrm{~nm}$. In other words, the extended deposition time of $100 \mathrm{~s}$ does not assist the growth of nanoparticles, though it provides more opportunity for hydrogen ions to absorb and discharge on the electrode. Consequently, further growth of Pt nanoparticles is hindered due to the interference of hydrogen gas evolution with platinum deposition. 3.3b Pulse potential electrodeposition: As mentioned above, the optimized sample prepared by the potentiostatic technique was selected as $\mathrm{Pt}_{2} / \mathrm{CNT}$ electrode for which platinum nanoparticles were deposited under $-0.6 \mathrm{~V}$ for $100 \mathrm{~s}$. However, in order to improve the catalytic behavior of the obtained CNTs, a more uniform distribution of Pt nanoparticles with a smaller size is needed to be obtained. For this purpose, the deposition of Pt nanoparticles was carried out by the pulse electrodeposition technique which involved a swift alternating of the potential between a cathodic value and the open circuit potential (OCP) at which no net current flowed through the external circuit. According to Table 1, the cathodic potential of $-0.6 \mathrm{~V}$ was selected as $E_{o n}$ and it was applied for three constant durations of $\mathrm{T}_{\text {on }}=10,50$, and $100 \mathrm{~s}$, while $\mathrm{E}_{\text {off }}$ was OCP (i.e., $-0.35 \mathrm{~V}$ ) which was applied for two durations of $\mathrm{T}_{\text {off }}=$ 10 and $100 \mathrm{~s}$ in 10 consecutive cycles. The influence of various cathodic pulse durations $\left(\mathrm{T}_{\mathrm{on}}\right)$ and current-off times $\left(\mathrm{T}_{\text {off }}\right)$ on the surface morphology of Pt-modified CNTs is illustrated in Figure 9. According to Figures 9a and $9 \mathrm{~b}, \mathrm{Pt}_{5}$ nanoparticles that are deposited on functionalized CNTs after 10 cycles of $\mathrm{E}_{\text {on }}=-0.6 \mathrm{~V}, \mathrm{~T}_{\text {on }}=$ $10 \mathrm{~s}, \mathrm{E}_{\text {off }}=-0.35 \mathrm{~V}$, and $\mathrm{T}_{\text {off }}=100 \mathrm{~s}$ are not distributed uniformly. Actually, $\mathrm{Pt}_{5}$ nanoparticles deposit on the active sites of the electrode during the first short cathodic pulse and since metal ions do not have enough time to deposit, a few embryos are nucleated. In the subsequent cathodic pulses, since the reduction of platinum ions on the surface of CNTs requires high nucleation energy, $\mathrm{Pt}_{5}$ nanoparticles tend to deposit on the previously generated nuclei, resulting in the formation of a 


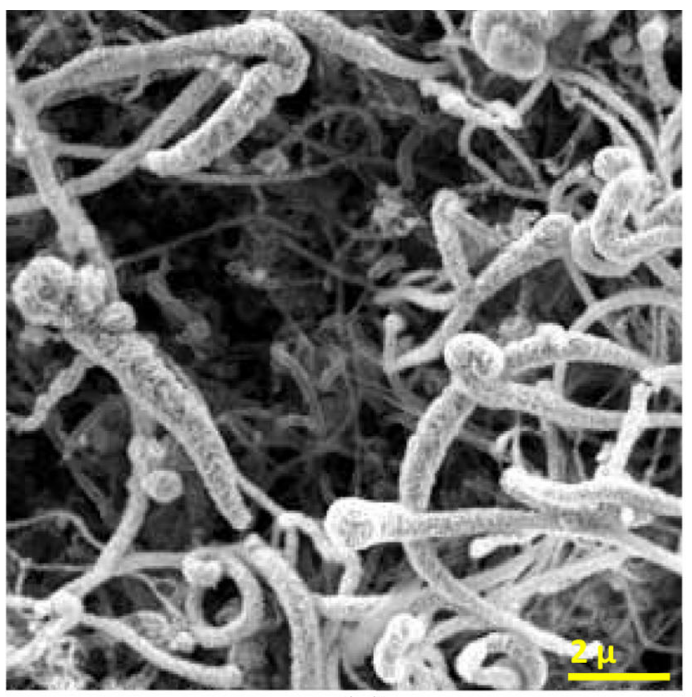

(a)

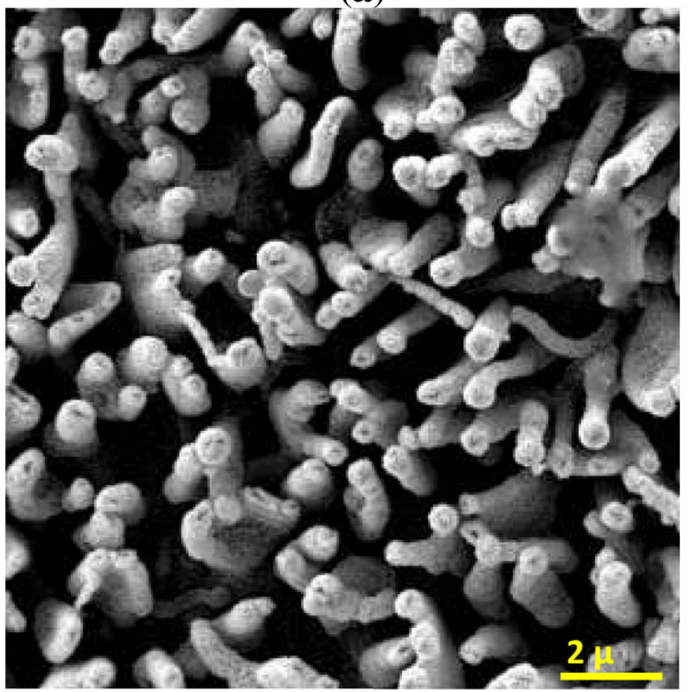

(c)

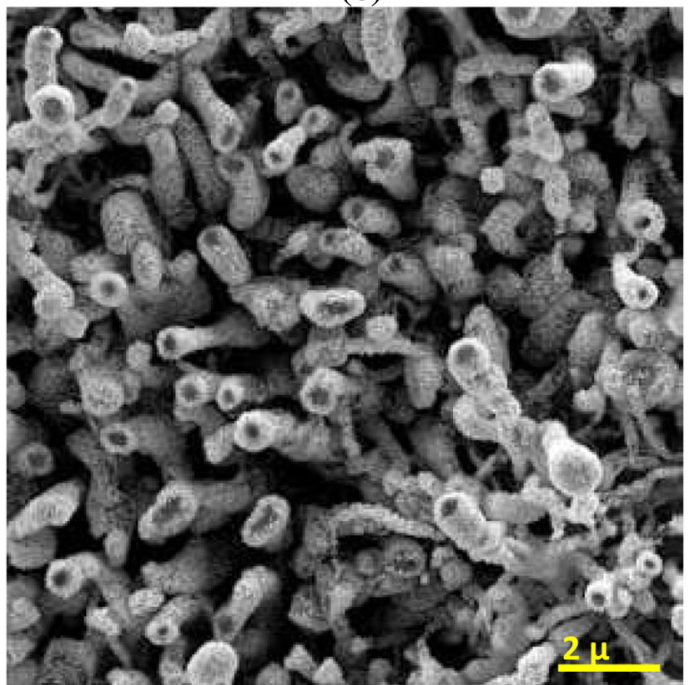

(e)

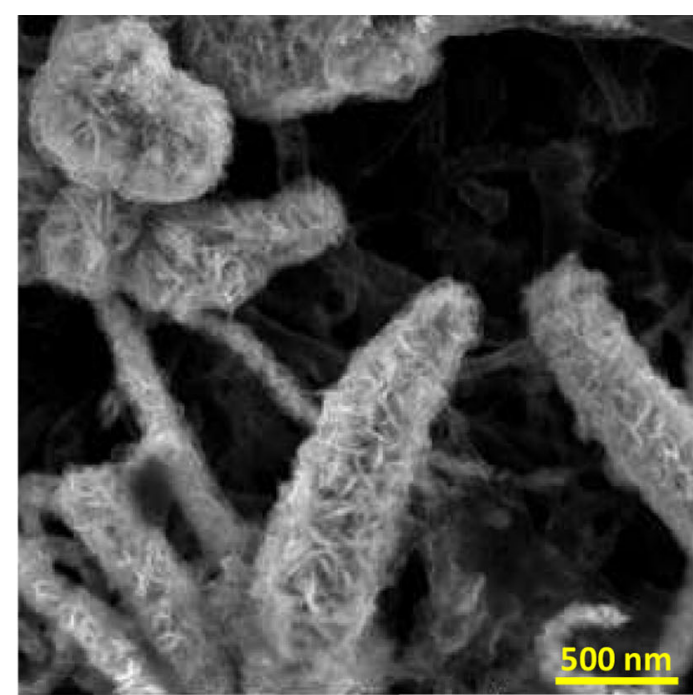

(b)

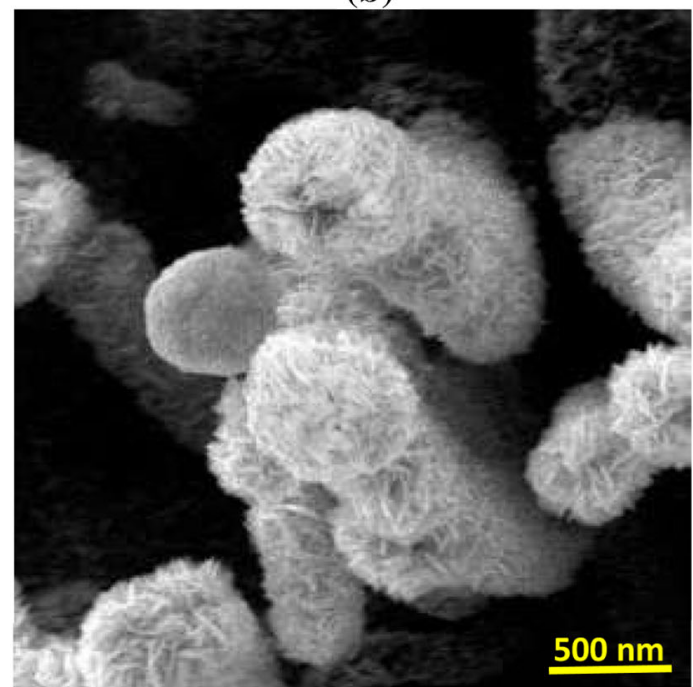

(d)

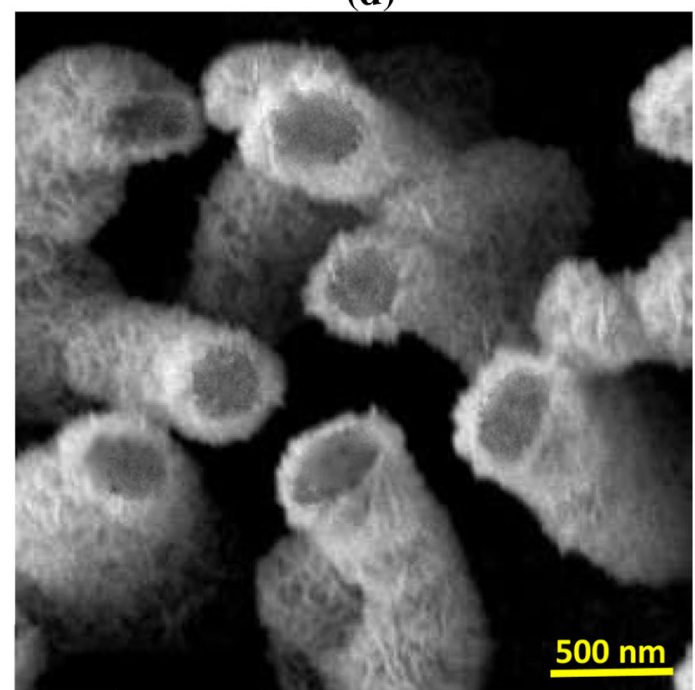

(f)

Figure 9. SEM images of functionalized CNTs after the pulse deposition of Pt nanoparticles prepared under the condition of $\mathrm{E}_{\mathrm{on}}=-0.6 \mathrm{~V}$ and $\mathrm{E}_{\text {off }}=-0.35 \mathrm{~V}$; (a), (b) $\mathrm{Pt}_{5} / \mathrm{CNT}\left(\mathrm{T}_{\mathrm{on}}=10 \mathrm{~s}\right.$, $\left.\mathrm{T}_{\text {off }}=100 \mathrm{~s}\right) ;(\mathrm{c}),(\mathrm{d}) \mathrm{Pt}_{6} / \mathrm{CNT}\left(\mathrm{T}_{\mathrm{on}}=50 \mathrm{~s}, \mathrm{~T}_{\text {off }}=10 \mathrm{~s}\right)$; (e), (f) Pt $7 / \mathrm{CNT}\left(\mathrm{T}_{\mathrm{on}}=100 \mathrm{~s}\right.$, $\left.\mathrm{T}_{\mathrm{off}}=10 \mathrm{~s}\right)$. 
non-uniform and inhomogeneous structure. On the other hand, due to a prolonged current-off time, platinum nanoparticles find sufficient opportunity to grow, and particles with the average size of $150 \mathrm{~nm}$ are obtained. Additionally, because of the longer pulse pause, hydrogen evolution accompanying the growth of $\mathrm{Pt}_{5}$ particles may disturb CNTs orientation and induce structural inhomogeneity. As can be seen from Figures 9c and 9d, when $\mathrm{T}_{\text {on }}$ is increased to $50 \mathrm{~s}$ and $\mathrm{T}_{\text {off }}$ is decreased to $10 \mathrm{~s}$, $\mathrm{Pt}_{6}$ nanoparticles mainly concentrate on the tips of CNTs as spherical clusters but they are also evenly distributed at the sidewalls of nanotubes with an average size of $50 \mathrm{~nm}$. Nanotube tips are generally believed to be more reactive than the sidewalls due to their stronger electrical field; thus, the adsorption affinity of CNTs tips for the attraction of the platinum ions is more intense than that of the sidewalls. ${ }^{28}$ As a result, during the cathodic cycles which are applied for the relatively short duration of $50 \mathrm{~s}$, $\mathrm{Pt}_{6}$ nanoparticles principally tend to deposit on the CNTs tips and they have less chance to form a thick layer on the sidewalls. To overcome this issue, the surface coverage can be tuned with the deposition time in cathodic pulses. Figures $9 \mathrm{e}$ and $9 \mathrm{f}$ demonstrate that under the same deposition condition, as $\mathrm{T}_{\text {on }}$ is increased to $100 \mathrm{~s}$, $\mathrm{Pt}_{7}$ nanoparticles are mainly dispersed at the sidewalls rather than the tips of CNTs, and walls are uniformly covered with a dense network of metal nanoparticles. In this case, the deposition of particles on the external wall of nanotubes fills the spaces between CNTs, promoting the formation of a more compact structure. Comparing Figures $9 \mathrm{~d}$ and $9 \mathrm{f}$ indicates that the particle size is almost unchanged at about $50 \mathrm{~nm}$ due to the short off-current pulses $\left(\mathrm{T}_{\text {off }}=10 \mathrm{~s}\right)$ which do not facilitate the excessive growth of $\mathrm{Pt}_{7}$ nanoparticles. A comparison of Figures $7 \mathrm{c}$ and $7 \mathrm{~d}$ with $9 \mathrm{e}$ and $9 \mathrm{f}$ reveals that the particle size and surface coverage can be controlled by the electrodeposition technique, and the $\mathrm{Pt}_{7} / \mathrm{CNT}$ electrode prepared by pulse potential deposition exhibit a highly uniform and compact structure of more refined platinum nanoparticles on the walls of CNTs as compared to the $\mathrm{Pt}_{2} / \mathrm{CNT}$ electrode prepared by the potentiostatic technique.

\subsection{Electrocatalytic performance of Pt-modified CNTs}

In order to investigate the influence of the electrodeposition technique upon the electrocatalytic activity of Pt-modified CNTs, $\mathrm{Pt}_{2} / \mathrm{CNT}$ and $\mathrm{Pt}_{7} / \mathrm{CNT}$ electrodes were chosen as the optimal samples and the methanol oxidation efficiencies of these two electrodes were compared. To remove surface contaminations prior to methanol oxidation analyses, $\mathrm{CV}$ experiments were conducted in a $0.5 \mathrm{M} \mathrm{H}_{2} \mathrm{SO}_{4}$ solution with potentials

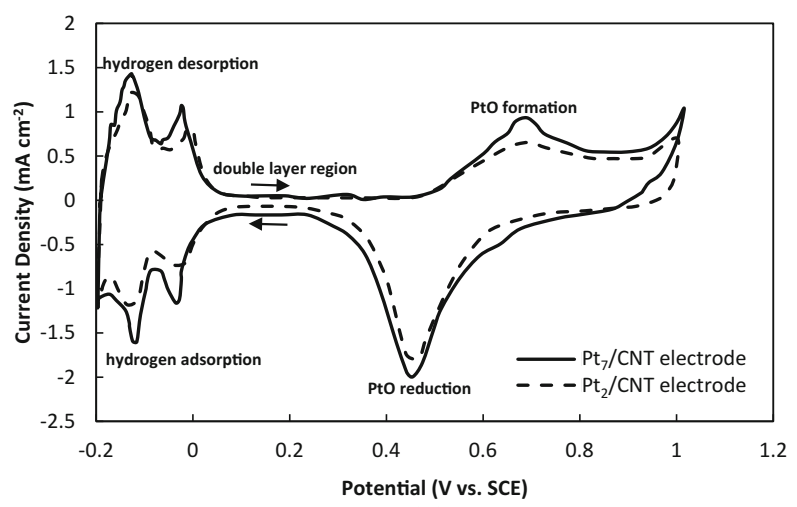

(a)

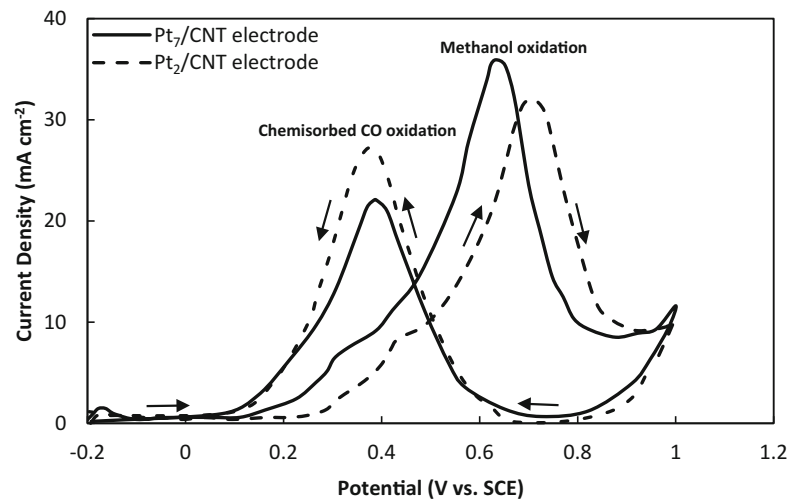

(b)

Figure 10. Cyclic voltammograms of $\mathrm{Pt}_{2} / \mathrm{CNT}$ and $\mathrm{Pt}_{7} / \mathrm{CNT}$ electrodes in $\mathrm{N}_{2}$ saturated (a) $0.5 \mathrm{M} \mathrm{H}_{2} \mathrm{SO}_{4}$ and (b) $0.5 \mathrm{M} \mathrm{H}_{2} \mathrm{SO}_{4}+1 \mathrm{M} \mathrm{CH}_{3} \mathrm{OH}$ aqueous solutions, at a scan rate of $50 \mathrm{mV} \mathrm{s}^{-1}$.

ranging from -0.2 to $1 \mathrm{~V}$ at a sweep rate of $50 \mathrm{mV} \mathrm{s}^{-1}$. Figure 10a depicts that the cyclic voltammograms of $\mathrm{Pt}_{2} / \mathrm{CNT}$ and $\mathrm{Pt}_{7} / \mathrm{CNT}$ electrodes are similar to that of a polycrystalline $\mathrm{Pt}$ electrode. ${ }^{29}$ In the forward scan, two hydrogen desorption peaks and a double-layer region are present, followed by an oxidation peak that is ascribed to the formation of PtO via the following reactions;

$\mathrm{Pt}+\mathrm{H}_{2} \mathrm{O} \rightarrow \mathrm{Pt}-\mathrm{OH}_{\mathrm{ads}}+\mathrm{H}^{+}+\mathrm{e}^{-}$
$\mathrm{Pt}-\mathrm{OH}_{\mathrm{ads}} \rightarrow \mathrm{Pt}-\mathrm{O}+\mathrm{H}^{+}+\mathrm{e}^{-}$

The PtO layer is reduced during the reverse scan, and two hydrogen adsorption peaks are observed after the double-layer region. All the potential regions are nearly identical for $\mathrm{Pt}_{2} / \mathrm{CNT}$ and $\mathrm{Pt}_{7} / \mathrm{CNT}$ electrodes; however, the current intensities at hydrogen adsorption/desorption and $\mathrm{Pt}$ oxidation/reduction peaks are higher for the sample prepared by pulse deposition. The higher current values at hydrogen desorption peaks for the sample prepared by pulse deposition indicates expedited desorption of hydrogen from the surface of the $\mathrm{Pt}_{7} / \mathrm{CNT}$ electrode that can have a beneficial impact 
on the catalytic activity of the electrode. Moreover, the higher current intensity of platinum oxidation peak suggests that a high quantity of $\mathrm{Pt}-\mathrm{O}$ and $\mathrm{Pt}-\mathrm{OH}$ species are produced on the surface of the $\mathrm{Pt}_{7} / \mathrm{CNT}$ electrode which can subsequently contribute to the oxidation of the adsorbed intermediates during methanol oxidation. ${ }^{30}$ The superior electrochemical activity of the pulse plated electrode is owing to the uniform distribution of refined platinum nanoparticles on the sidewalls of CNTs in the $\mathrm{Pt}_{7} / \mathrm{CNT}$ electrode. Accordingly, the higher surface coverage of CNTs by $\mathrm{Pt}_{7}$ nanoparticles provides a larger active surface and boosts the catalytic property of this electrode.

According to Figure 10b, the methanol oxidation efficiencies of the electrodes are evaluated by $\mathrm{CV}$ analysis in an $\mathrm{N}_{2}$ saturated $0.5 \mathrm{M} \mathrm{H}_{2} \mathrm{SO}_{4}+1 \mathrm{M} \mathrm{CH}_{3} \mathrm{OH}$ solution in the potential range of -0.2 to $1 \mathrm{~V}$ at a rate of $50 \mathrm{mV} \mathrm{s}^{-1}$. While similar behavior has been observed for methanol oxidation on pure platinum electrodes in acidic solutions, the peak potentials obtained for $\mathrm{Pt}_{7} / \mathrm{CNT}$ and $\mathrm{Pt}_{2} / \mathrm{CNT}$ electrodes are less positive than that reported for pure Pt electrodes. ${ }^{31}$ This is due to the presence of functional groups such as carbonyl and hydroxyl on the surface of functionalized CNTs which serve as active oxygen sites and facilitate the oxidation of methanol and enhance the electrocatalytic activity of the electrodes. The oxidation of methanol on $\mathrm{Pt}$ is carried out through the following reactions;

$$
\begin{aligned}
& \mathrm{Pt}+\mathrm{CH}_{3} \mathrm{OH} \rightarrow \mathrm{Pt}(\mathrm{CO})_{\mathrm{ads}}+4 \mathrm{H}^{+}+4 \mathrm{e}^{-} \\
& \mathrm{Pt}+\mathrm{H}_{2} \mathrm{O} \rightarrow \mathrm{Pt}(\mathrm{OH})_{\mathrm{ads}}+\mathrm{H}^{+}+\mathrm{e}^{-} \\
& \mathrm{Pt}(\mathrm{CO})_{\mathrm{ads}}+\mathrm{Pt}(\mathrm{OH})_{\mathrm{ads}} \rightarrow 2 \mathrm{Pt}+\mathrm{CO}_{2}+\mathrm{H}^{+}+\mathrm{e}^{-}
\end{aligned}
$$

Accordingly, the overall equation can be considered as follows;

$$
\mathrm{CH}_{3} \mathrm{OH}+\mathrm{H}_{2} \mathrm{O} \rightarrow \mathrm{CO}_{2} \uparrow+6 \mathrm{H}^{+}+6 \mathrm{e}^{-}
$$

Based on Figure 10b, the impacts of deposition techniques on the electroactivity of the prepared electrodes for methanol oxidation can be easily identified by examining the onset potentials, peak current densities of methanol oxidation, and the ratios of forward to reverse peak current densities. The onset potential is related to the breaking of $\mathrm{C}-\mathrm{H}$ bonds in methanol molecules that are absorbed on $\mathrm{Pt}$ nanoparticles, and this parameter is $0.28 \mathrm{~V}$ and $0.17 \mathrm{~V}$ for $\mathrm{Pt}_{2} / \mathrm{CNT}$ and $\mathrm{Pt}_{7} / \mathrm{CNT}$ electrodes, respectively. These values indicate that the morphological structure of the electrode prepared by pulse deposition reduces the initial required energy and promotes methanol oxidation. As the potential is swept toward more positive values in the forward scan, the adsorption of methanol molecules on the Pt nanoparticles leads to the formation of $\operatorname{Pt}(\mathrm{CO})_{\mathrm{ads}}$ (Eq. (3)), and simultaneously, the oxidation of water occurs and $\mathrm{Pt}(\mathrm{OH})_{\text {ads }}$ is generated (Eq. (4)). The adsorption and oxidation reactions culminate in peaks at 0.71 and $0.63 \mathrm{~V}$ for $\mathrm{Pt}_{2} / \mathrm{CNT}$ and $\mathrm{Pt}_{7} / \mathrm{CNT}$ electrodes, respectively, and in parallel, Pt nanoparticles which are poisoned by $\mathrm{CO}$ can be regenerated via the reaction of adsorbed $\mathrm{CO}$ with $\mathrm{OH}$ to yield $\mathrm{CO}_{2}$ (Eq. (5)). By sweeping the voltage to more anodic values, the oxidation of methanol is accompanied by the formation of more byproducts which have a blocking/poisoning effect and decrease the current density. The lower value of the potential at the oxidation peak in the forward scan for the $\mathrm{Pt}_{7} / \mathrm{CNT}$ electrode in comparison to that of the $\mathrm{Pt}_{2} / \mathrm{CNT}$ electrode is indicative of the reduced required potential for methanol oxidation on the electrode prepared by pulse deposition. Moreover, the current value at this peak is higher for the $\mathrm{Pt}_{7} / \mathrm{CNT}$ electrode in comparison to the $\mathrm{Pt}_{2} / \mathrm{CNT}$ electrode. SEM observations in Figures $7 \mathrm{c}, 7 \mathrm{~d}$ and $9 \mathrm{e}$, 9f can be used to justify the superior electrocatalytic performance of the pulse plated electrode over the sample prepared by the potentiostatic technique. As compared to the $\mathrm{Pt}_{2} / \mathrm{CNT}$ electrode, the $\mathrm{Pt}_{7} / \mathrm{CNT}$ electrode possesses a highly compact structure with more refined and uniformly distributed platinum nanoparticles which provide a higher density of exposed active sites for trapping methanol molecules, leading to the enhanced electrocatalytic performance of the specimen prepared by pulse deposition.

In the reverse sweep, the oxidation peaks signify the desorption of $\mathrm{CO}$ generated through methanol oxidation during the forward scan, and the desorbed $\mathrm{CO}$ is thereupon converted to $\mathrm{CO}_{2}$. It should be noted that while Pt nanoparticles are considered as effective catalysts for methanol oxidation, they tend to be self-poisoned by reaction intermediates such as $\mathrm{CO}$ which are formed during dehydrogenation of the methanol. The electrode efficiency on methanol oxidation can be evaluated with regard to the tolerance of $\mathrm{Pt}$ nanoparticles towards poisoning by carbon monoxide in terms of a ratio of the forward to reverse peak current densities. According to Figure $10 \mathrm{~b}$, this ratio is estimated to be 1.15 and 1.73 for $\mathrm{Pt}_{2} / \mathrm{CNT}$ and $\mathrm{Pt}_{7} / \mathrm{CNT}$ electrodes, respectively, representing the superior poisoning tolerance of the $\mathrm{Pt}_{7} / \mathrm{CNT}$ electrode. The enhanced tolerance of the pulse plated electrode to $\mathrm{CO}$ poisoning is attributed to the compact coverage of CNTs with well-dispersed $\mathrm{Pt}_{7}$ nanoparticles that can effectively inhibit the adsorption of $\mathrm{CO}$ during the anodic sweep and subsequently decrease $\mathrm{CO}$ poisoning in the reverse sweep. This attribute, along with the slightly lower onset and oxidation peak potentials and significantly higher current density in the forward scan for the $\mathrm{Pt}_{7} / \mathrm{CNT}$ electrode confirm the superior electrocatalytic activity and lower self-poisoning of the 


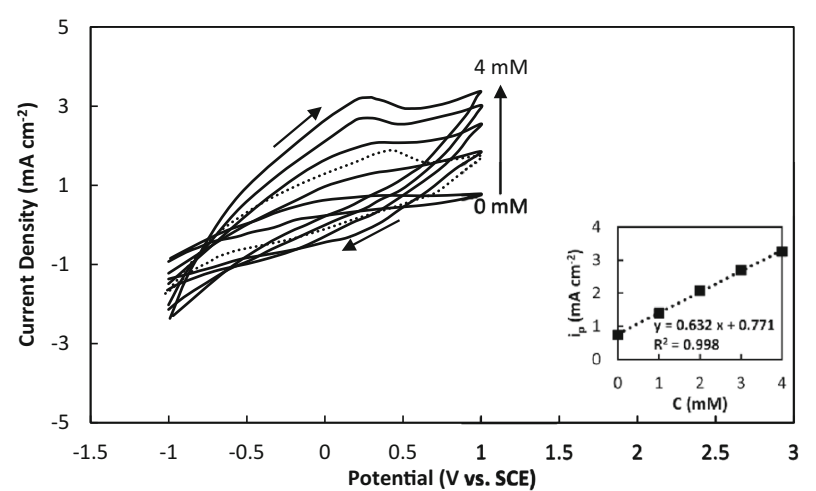

(a)

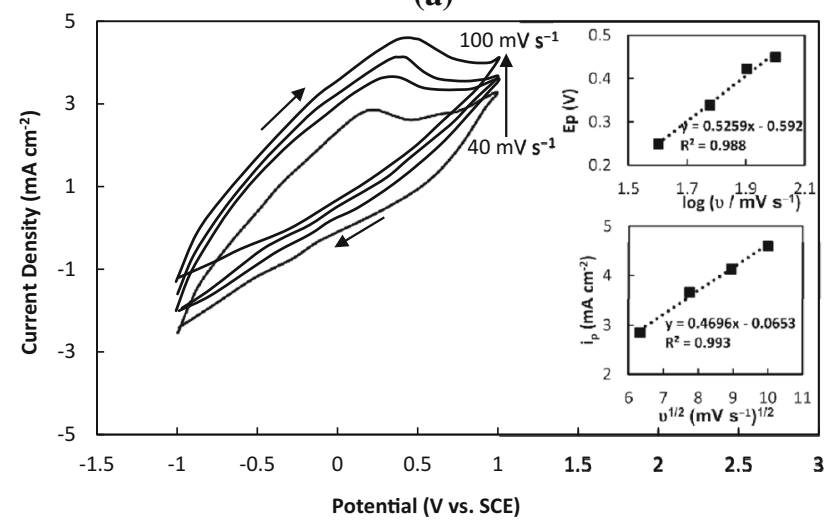

(b)

Figure 11. Cyclic voltammetric response of the $\mathrm{Pt}_{7} / \mathrm{CNT}$ electrode to increasing (a) concentrations of sulfide from 0 to $4 \mathrm{mM}(\mathrm{pH}=6.8)$ at a scan rate of $50 \mathrm{mV} \mathrm{s}^{-1}$ (the dashed curve belongs to the non-modified CNT electrode at a concentration of $4 \mathrm{mM}$ ); (b) scan rates from 40 to $100 \mathrm{mV} \mathrm{s}^{-1}$ at a sulfide concentration of $4 \mathrm{mM}$.

electrode prepared by pulse deposition as compared to the specimen fabricated by the potentiostatic technique.

\subsection{The performance of pulse plated Pt/CNT electrodes as electrochemical sensors}

Based on the above analysis, the $\mathrm{Pt}_{7} / \mathrm{CNT}$ electrode which was fabricated by the pulse potential deposition of $\mathrm{Pt}$ nanoparticles on 10 cycles functionalized CNTs exhibited the optimized morphological and electrochemical properties. To further verify the crucial role of platinum nanoparticles in the electrochemical behavior of the CNTs, sensing properties of the $\mathrm{Pt}_{7} / \mathrm{CNT}$ electrode for the electrochemical detection and oxidation of sulfide ions was examined. Figure 11a displays the cyclic voltammetric response of the $\mathrm{Pt}_{7} / \mathrm{CNT}$ electrode to increasing concentrations of sulfide ions from 0 to $4 \mathrm{mM}(\mathrm{pH}=6.8)$ over the potential range of -1 to $1 \mathrm{~V}$ at a scan rate of $50 \mathrm{mV} \mathrm{s}^{-1}$. The $\mathrm{CV}$ curve of the functionalized but non-modified CNT electrode was also plotted in a solution containing $4 \mathrm{mM}$ sulfide for comparison (dashed line). The anodic currents measured in the absence of sulfide ions are negligibly small compared to those measured in its presence, indicating that the anodic currents are definitely due to the oxidation of sulfide ions. As the concentration of sulfide is increased to $4 \mathrm{mM}$, an oxidative current emerges at about $-0.7 \mathrm{~V}$ and it continues to rise until it reaches an oxidation peak at $0.25 \mathrm{~V}$, after which a steady response is obtained. It should be emphasized that hydrogen sulfide is generally considered as a weak acid and in an aqueous solution; it tends to become deprotonated to form the mono-protonated hydrogen sulfide anion;

$\mathrm{H}_{2} \mathrm{~S} \rightarrow \mathrm{HS}^{-}+\mathrm{H}^{+}$

The mechanism of the action of Pt nanoparticles on the sensing properties of Pt-modified CNTs for the detection of sulfide ions in aqueous media is dependent upon $\mathrm{pH}$. In alkaline solutions, $\mathrm{HS}^{-}$is the predominant species, and sulfide oxidation on platinum results in the formation of elemental sulfur bonded onto the catalyst nanoparticles, according to the following reactions: ${ }^{33}$

$\mathrm{Pt}+\mathrm{HS}^{-} \rightarrow \mathrm{Pt}\left(\mathrm{HS}^{-}\right)_{\mathrm{ads}}$
$\mathrm{Pt}\left(\mathrm{HS}^{-}\right)_{\mathrm{ads}}+\mathrm{OH}^{-} \rightarrow \mathrm{S}+\mathrm{H}_{2} \mathrm{O}+2 \mathrm{e}^{-}+\mathrm{Pt}$

However, in acidic solutions, the presence of $\mathrm{H}_{2} \mathrm{~S}$ dominates, and the oxidation of sulfide to sulfate is favored, through to the following reactions: ${ }^{17}$

$\mathrm{Pt}+\mathrm{H}_{2} \mathrm{~S} \rightarrow \mathrm{Pt}\left(\mathrm{H}_{2} \mathrm{~S}\right)_{\text {ads }}$

$\mathrm{Pt}\left(\mathrm{H}_{2} \mathrm{~S}\right)_{\text {ads }}+4 \mathrm{H}_{2} \mathrm{O} \rightarrow \mathrm{SO}_{4}^{2-}+8 \mathrm{e}^{-}+10 \mathrm{H}^{+}+\mathrm{Pt}$

It has been demonstrated that at $\mathrm{pH} 6.8$ and $25^{\circ} \mathrm{C}$, about 30 and $70 \mathrm{vol} . \%$ of the sulfide will be present as $\mathrm{HS}^{-}$ and $\mathrm{H}_{2} \mathrm{~S}$, respectively. ${ }^{32}$ Thus, $\mathrm{H}_{2} \mathrm{~S}$ is the predominant species in the acidic solution employed in this research, and the oxidation peaks in Figure 11a can be ascribed to the adsorption and oxidation of $\mathrm{H}_{2} \mathrm{~S}$ on $\mathrm{Pt}_{7}$ nanoparticles through Eq. (10) and Eq. (11). No reduction peak is detected in the reverse scan, confirming that the electrochemically generated oxidation products do not undergo a reduction in the potential range studied. Analysis of the dashed CV curve reveals that at a sulfate concentration of $4 \mathrm{mM}$, the functionalized but non-modified CNT electrode exhibits a decreased oxidation current values compared to those of the $\mathrm{Pt}_{7} / \mathrm{CNT}$ electrode, with an oxidation peak at $0.48 \mathrm{~V}$. It can be concluded that the catalytic properties of platinum nanoparticles deposited on the sidewalls of CNTs account for the slight shift of the oxidation peak to less positive potentials and higher current densities, leading to an enhanced capability for the electrochemical detection of sulfide. The inset in Figure 11a illustrates that for the $\mathrm{Pt}_{7} / \mathrm{CNT}$ electrode, peak current values vary linearly over the sulfide concentration range with a sensitivity of $0.632 \mu \mathrm{A \mu M} \mathrm{M}^{-1} \mathrm{~cm}^{-2}$ 


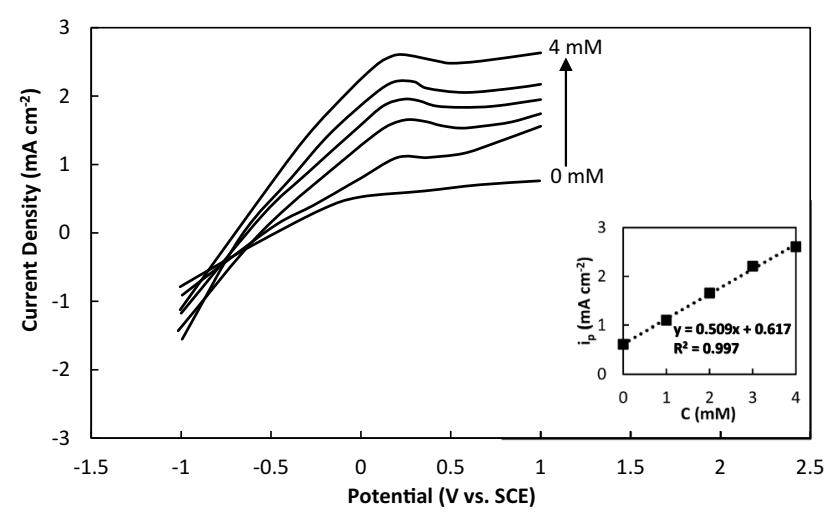

Figure 12. Differential pulse voltammograms obtained at the $\mathrm{Pt}_{7} / \mathrm{CNT}$ electrode for the oxidation of different concentrations of sulfide from 0 to $4 \mathrm{mM}(\mathrm{pH}=6.8)$ at a scan rate of $50 \mathrm{mV} \mathrm{s}^{-1}$ (step potential: $0.01 \mathrm{~V}$, modulation amplitude: $0.01 \mathrm{~V}$, modulation time: $0.05 \mathrm{~s}$, interval time: $1 \mathrm{~s}$ ).

that is substantially higher than that measured for the non-modified CNTs electrode $\left(0.081 \mu \mathrm{A} \mu \mathrm{M}^{-1} \mathrm{~cm}^{-2}\right.$, results not shown here).

Further assessment of the sulfide oxidation process was carried out by investigating the influence of different scan rates $\left(40,60,80\right.$ and $\left.100 \mathrm{mV} \mathrm{s}^{-1}\right)$ on the $\mathrm{CV}$ curves of the $\mathrm{Pt}_{7} / \mathrm{CNT}$ electrode at a sulfide concentration of $4 \mathrm{mM}$. Figure $11 \mathrm{~b}$ demonstrates that the oxidation peaks shift to more positive potentials and higher current densities as the scan rate is increased. Such behavior is typical of a diffusion-controlled oxidation process in which at higher scan rates, sulfide concentration gradient increases in the solution and sulfide anions have to diffuse from the bulk electrolyte to become oxidized on the sidewalls of CNTs and deposited Pt nanoparticles. As depicted in the insets in Figure 11b, the linearity of $E_{p}$ vs. $\log v$ as well as $i_{p}$ vs. $v^{l / 2}$ plots further confirms that the oxidation of sulfide anions involves an irreversible electron transfer process that is under diffusion control.

In order to investigate which voltammetric technique is more sensitive for the detection of sulfide ions on the pulse plated electrode, DPV was employed over the concentration range of $0-4 \mathrm{mM}$. Operating conditions for DPV studies were stepped potential of $5 \mathrm{mV}$, modulation amplitude of $25 \mathrm{mV}$, modulation time of $0.05 \mathrm{~s}$, and interval time of $1 \mathrm{~s}$. Figure 12 shows differential pulse voltammograms for sulfide oxidation on the $\mathrm{Pt}_{7} / \mathrm{CNT}$ electrode at a scan rate of $50 \mathrm{mV} \mathrm{s}^{-1}$, along with corresponding calibration graphs of the oxidation current versus sulfide concentration. Based on the corresponding linear regression equation, the sensitivity value estimated by DPV is $0.509 \mu \mathrm{A} \mu \mathrm{M}^{-1} \mathrm{~cm}^{-2}$ that is relatively lower than the $0.632 \mu \mathrm{A} \mu \mathrm{M}^{-1} \mathrm{~cm}^{-2}$ value obtained by $\mathrm{CV}$. Thus, the $\mathrm{CV}$ method appears to be more efficient for achieving the highest sensitivity on the developed sensor.

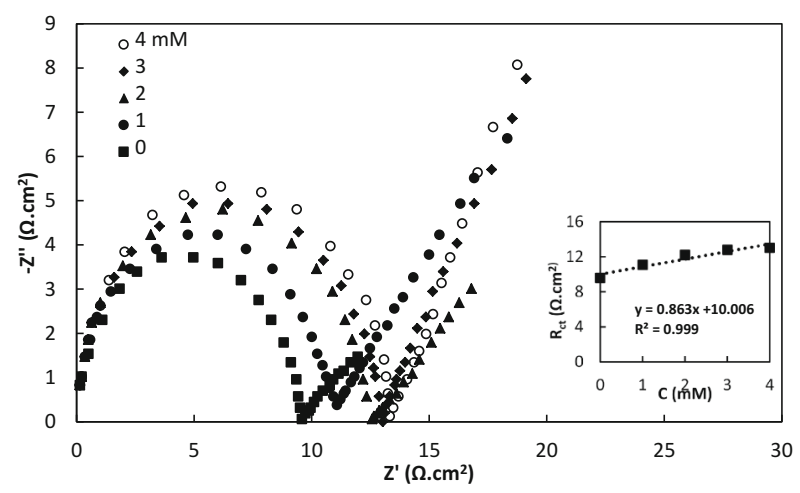

Figure 13. Nyquist plots for the $\mathrm{Pt}_{7} / \mathrm{CNT}$ electrode recorded in electrolytes containing different concentrations of sulfide between 0 and $4 \mathrm{mM}$. Frequency range: $100 \mathrm{kHz}-0.05 \mathrm{~Hz}$, potential:0.25 V, AC amplitude: $10 \mathrm{mV}$.

The EIS technique was used to further investigate the oxidation performance of the designed sensor. Figure 13 represents the Nyquist plots of the $\mathrm{Pt}_{7} / \mathrm{CNT}$ electrode in electrolytes containing different concentrations of sulfide between 0 and $4 \mathrm{mM}$, recorded at a frequency range of $100 \mathrm{kHz}$ to $0.05 \mathrm{~Hz}$ at a potential of $0.25 \mathrm{~V}$ with an AC excitation amplitude of $10 \mathrm{mV}$. The Nyquist diagrams exhibit a capacitive loop at higher frequencies associated with the double layer capacity, followed by a straight line at lower frequencies, which is the typical feature of a diffusion-controlled process. ${ }^{34}$ It is also evident that with an increase in the sulfide contraction, the charge-transfer resistance $\left(\mathrm{R}_{\mathrm{ct}}\right)$ at the electrode/solution interface increases while the values of the electrochemical double layer capacitance and diffusional impedance decrease. This trend can be attributed to the formation of sulfide oxidation products such as sulfate species that cause fouling effect at the electrode surface. The chargetransfer resistance which equals the semicircle diameter controls the electron-transfer kinetics of the oxidation of sulfide to sulfate at the electrode interface. The sensing performance of the $\mathrm{Pt}_{7} / \mathrm{CNT}$ electrode was evaluated via monitoring the changes in $\mathrm{R}_{\mathrm{ct}}$ upon the analysis of different concentrations of sulfide ions. The inset in Figure 13 displays the calibration plot of the charge transfer resistance values obtained for the $\mathrm{Pt}_{7} / \mathrm{CNT}$ sensor as a function of sulfide concentration. The sensor response varies linearly $\left(\mathrm{R}^{2}=0.999\right)$ with the concentration, and the detection limit is estimated as $0.29 \mu \mathrm{M}$ at a signalto-noise ratio of 3.

In order to determine the lower limit of detection, which is the lowest concentration of sulfide that can be detected by the sensor, the current-time response of the $\mathrm{Pt}_{7} / \mathrm{CNT}$ electrode was plotted at the oxidation potential of $0.25 \mathrm{~V}$. According to Figure 14, the measurements were performed with the successive addition of $10 \mu \mathrm{M}$ 
sulfide after each 60 seconds. The $\mathrm{Pt}_{7} / \mathrm{CNT}$ sensor responds quickly to these continuous sulfide additions, producing steady-state signals during repeated $60 \mathrm{sec}-$ onds. The response time (i.e., the time required to reach $95 \%$ of the maximum steady-state current) is estimated to be within $5 \mathrm{~s}$, indicating the facile electron transfer process through the designed sensor. The inset in Figure 14 displays the calibration graph of the response current as a function of sulfide concentration, that is used for the calculation of the detection limit. It is evident that the $\mathrm{Pt}_{7} / \mathrm{CNT}$ electrode exhibits two separate linear sections in the concentration ranges of $0-40 \mu \mathrm{M}$ and $40-100 \mu \mathrm{M}$ for which the regression equations are $\mathrm{i}\left(\mu \mathrm{A} \mathrm{cm}^{-2}\right)=-5.2995+3.0971 \mathrm{C}(\mu \mathrm{M})\left(\mathrm{R}^{2}=\right.$ $0.989)$ and $\mathrm{i}\left(\mu \mathrm{A} \mathrm{cm}^{-2}\right)=-317.9+10.868 \mathrm{C}(\mu \mathrm{M})$ $\left(\mathrm{R}^{2}=0.997\right)$, respectively. The detection limit of

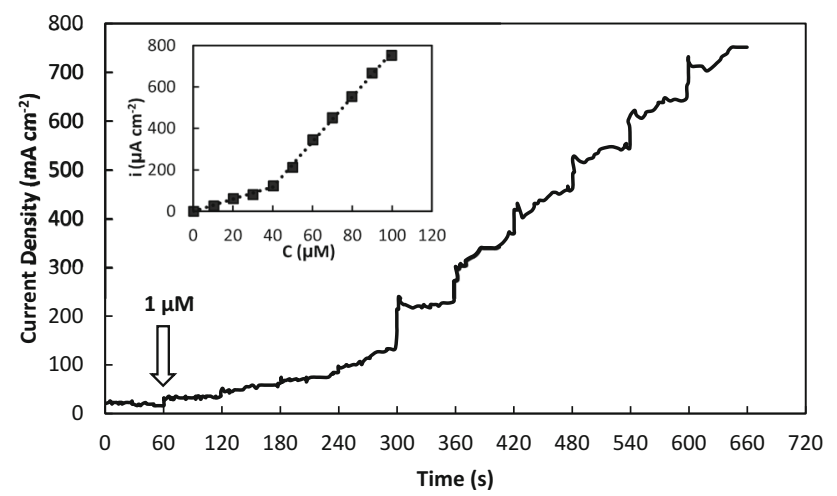

Figure 14. The amperometric response of the $\mathrm{Pt}_{7} / \mathrm{CNT}$ electrode to successive addition of sulfide at an applied potential of $0.25 \mathrm{~V}$ vs. SCE. the $\mathrm{Pt}_{7} / \mathrm{CNT}$ sensor is estimated to be $0.26 \mu \mathrm{M}$ at a signal-to-noise ratio of 3 . The amperometric results confirm the EIS measurements; however, since the limit of detection observed by the amperometric measurements is more precise, the lower detection limit of the designed sensor is considered as $0.26 \mu \mathrm{M}$. These data not only indicate the effectiveness of the designed electrode for the detection of low concentrations of sulfide in the range of $40-100 \mu \mathrm{M}$ but also confirm the capability of this electrode as a sensitively amperometric sensor to detect much lower concentrations of sulfide in the range of $0-40 \mu \mathrm{M}$. With regard to the values of sensitivity and detection limits reported for different types of carbon nanotubes, ${ }^{17}$ the enhanced sensitivity of the $\mathrm{Pt}_{7} / \mathrm{CNT}$ electrode towards changes in sulfide concentrations along with a low limit of detection reveals that the fabricated sensor can be reliably applied to monitor sulfide at trace levels for various industrial and environmental applications.

A comparison of the analytical performance of the $\mathrm{Pt}_{7} / \mathrm{CNT}$ electrode with other reported sulfide sensors is represented in Table 2. The analytical parameters of our designed sensor are comparable or superior to the results reported for the electroanalytical determination of sulfide at the surface of different modified electrodes.

Despite all promising features, CNT-based electrodes might undergo electric field-induced morphology changes that lead to the oxidative unzipping of carbon nanotubes to graphene nanoribbons, thereby impacting the performance and long term stability of the electrodes. ${ }^{42}$ To investigate the unzipping of the pulse plated $\mathrm{Pt}_{7} / \mathrm{CNT}$ sensor, the morphology of nanotubes

Table 2. Comparison of different electrochemical sensors for the determination of aqueous sulfide

\begin{tabular}{|c|c|c|c|c|}
\hline Electrode & $\begin{array}{c}\text { Sensitivity } \\
\left(\mu \mathrm{A} \mu \mathrm{M}^{-1} \mathrm{~cm}^{-2}\right)\end{array}$ & $\begin{array}{l}\text { Detection limit } \\
\qquad(\mu \mathrm{M})\end{array}$ & $\begin{array}{l}\text { Response time } \\
\text { (s) }\end{array}$ & References \\
\hline $\begin{array}{l}\text { Nickel powder-modified carbon composite } \\
\text { electrode (Ni-CCE) }\end{array}$ & 0.008 & 1.19 & 2 & {$\left[{ }^{35}\right]$} \\
\hline Glassy carbon electrode (GCE) & 0.057 & 0.1 & 10 & {$\left[{ }^{36}\right]$} \\
\hline $\begin{array}{l}\text { Vanadium pentoxide film-modified glassy } \\
\text { carbon electrode }\left(\mathrm{V}_{2} \mathrm{O}_{5}-\mathrm{GCE}\right)\end{array}$ & 0.089 & 1.9 & 8 & {$\left[{ }^{37}\right]$} \\
\hline $\begin{array}{l}\text { Copper complex and multiwall carbon } \\
\text { nanotubes-modified glassy carbon electrode } \\
(\mathrm{Cu}(\mathrm{II}) / \mathrm{MWCNT} / \mathrm{GCE})\end{array}$ & 0.034 & 1.2 & 1 & {$\left[{ }^{38}\right]$} \\
\hline $\begin{array}{l}\text { Reduced graphene sheets-modified glassy } \\
\text { carbon electrode (RGS- GCE) }\end{array}$ & 0.014 & 4.2 & 10 & {$\left[{ }^{39}\right]$} \\
\hline $\begin{array}{l}\text { Hematoxylin-modified pencil graphite electrode } \\
\text { (HMT-PGE) }\end{array}$ & 0.022 & 0.4 & 20 & {$\left[{ }^{40}\right]$} \\
\hline $\begin{array}{l}\text { Hematoxylin multi-walled carbon } \\
\text { nanotubes-modified carbon paste electrode } \\
\text { (HM-MWCNTs-CPE) }\end{array}$ & 0.1026 & 0.2 & 3 & {$\left[{ }^{41}\right]$} \\
\hline $\begin{array}{l}\text { Pulse plated Pt-modified carbon nanotube } \\
\text { electrode (Pt/CNT) }\end{array}$ & 0.632 & 0.26 & 5 & This work \\
\hline
\end{tabular}




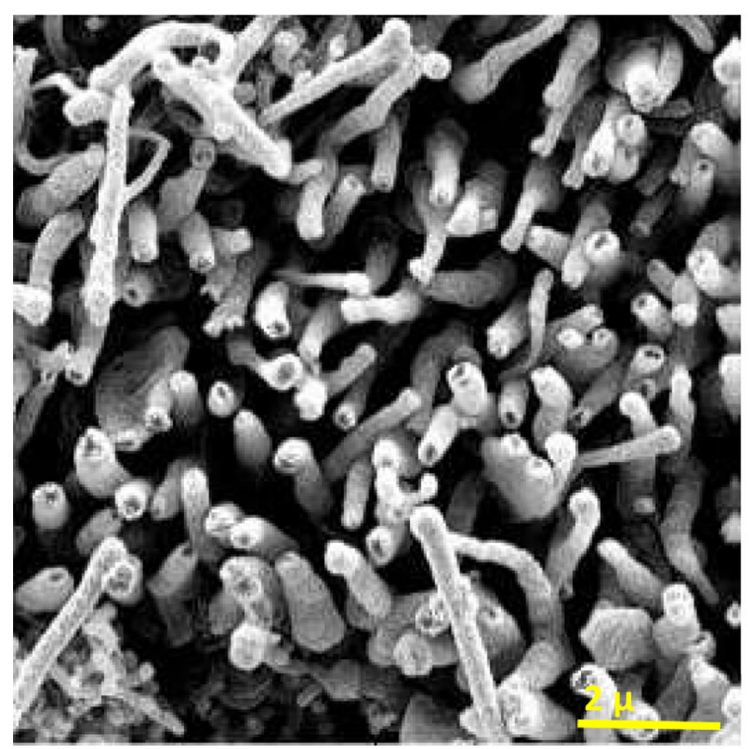

(a)

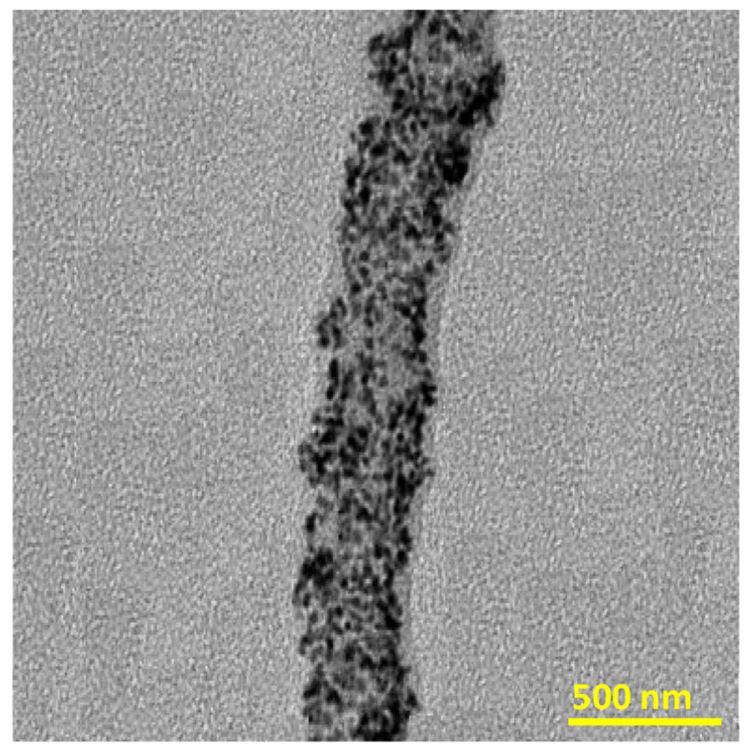

(b)

Figure 15. (a) SEM and (b) TEM images of the $\mathrm{Pt}_{7} / \mathrm{CNT}$ sensor after the oxidation of $4 \mathrm{mM}$ dissolved sulfide ions at the potential of $0.25 \mathrm{~V}$ vs. SCE for $24 \mathrm{~h}$.

was studied after the oxidation of $4 \mathrm{mM}$ dissolved sulfide ions at the potential of $0.25 \mathrm{~V}$ for $24 \mathrm{~h}$. The SEM and TEM images in Figures 15a and 15b depict that Pt-modified CNTs are stable and Pt nanoparticles are uniformly distributed at the CNTs surface. Moreover, no complete or partial exfoliation or unzipping of nanotubes can be observed after the electrochemical process, and the integrity of Pt-modified CNTs does not change after the sulfide oxidation. In other words, the applied potential of $0.25 \mathrm{~V}$ in the presence of $4 \mathrm{mM}$ sulfide ions does not generate sufficient electric field on the electrode/electrolyte interface and cannot trigger the transformation of CNTs to longitudinally unzipped graphene nanoribbons. This is justifiable because according to other researchers, even in the case of highly concentrated acid solutions, the onset potential for the unzipping of carbon nanotubes is much higher than the oxidation potential applied in the current study. ${ }^{43,44}$

\section{Conclusions}

The thermal CVD process was utilized to synthesize vertically aligned carbon nanotubes (CNTs) on stainless steel substrates. To catalyze the growth of nanotubes, a thin layer of cobalt catalyst nanoparticles was electrodeposited on the substrates under the optimum deposition potential of $-1.1 \mathrm{~V}$ vs. SCE, leading to the formation of bamboo-shaped CNTs with close ends. Functionalization and purification of CNTs by
10 cycles of electrochemical oxidation in sulfuric acid solution opened the tips of nanotubes while generating oxygen-containing functional groups, mainly carboxyl, at the sidewalls and tube endings. Surface modification of nanotubes was carried out by the electrodeposition of Pt nanoparticles on CNT-based electrodes, and the optimum operating parameters were determined as $\mathrm{E}=-0.6 \mathrm{~V}, \mathrm{t}=100 \mathrm{~s}$ and $\mathrm{E}_{\mathrm{on}}=-0.6 \mathrm{~V}$, $\mathrm{T}_{\text {on }}=100 \mathrm{~s}, \mathrm{E}_{\text {off }}=-0.35 \mathrm{~V}, \mathrm{~T}_{\text {off }}=10 \mathrm{~s}$ in the potentiostatic and pulse potential deposition techniques, respectively. The functionalized CNT-based electrode modified by pulse deposited Pt nanoparticles exhibited a superior catalytic performance towards methanol oxidation reaction accompanied by an improved tolerance to $\mathrm{CO}$ poisoning as compared to the electrode modified by the potentiostatically deposited particles. This was ascribed to the extremely uniform distribution of more refined platinum nanoparticles that provided a higher density of exposed active sites for trapping methanol molecules on the surface of the electrode fabricated by pulse deposition. The pulse plated Pt/CNT electrode could effectively detect dissolved sulfide with a sensitivity of $0.632 \mu \mathrm{A} \mu \mathrm{M}^{-1} \mathrm{~cm}^{-2}$ and a detection limit of $0.26 \mu \mathrm{M}$, and the oxidation of sulfide anions on the designed sensor involved the formation of sulfate species, rather than elemental sulfur, through an irreversible diffusion-controlled process. These data suggest the remarkable capabilities of the fabricated sensor as a promising candidate for numerous applications in water and wastewater treatment technologies. 


\section{References}

1. Raoof J B, Chekin F, Ojani R and Barari S 2013 Carbon paste electrode incorporating multi-walled carbon nanotube/ferrocene as a sensor for the electroanalytical determination of N-Acetyl-L-cysteine in the presence of tryptophan J. Chem. Sci. 12528

2. Artukovic E, Kaempgen M, Hecht D S, Roth S and Gruner G 2005 Transparent and flexible carbon nanotube transistors Nano Lett. 5757

3. Mananghaya M R 2015 Hydrogen adsorption of nitrogen-doped carbon nanotubes functionalized with 3d-block transition metals J. Chem. Sci. 127751

4. Rangom Y, Tang X and Nazar L F 2015 Carbon nanotube-based supercapacitors with excellent ac line filtering and rate capability via improved interfacial impedance ACS Nano 97248

5. Xiong Z, Yun Y S and Jin H J 2013 Applications of carbon nanotubes for lithium ion battery anodes Materials 6 1138

6. Ahammad A J S, Lee J J and Rahman M A 2009 Electrochemical sensors based on carbon nanotubes Sensors 9 2289

7. Szabo A, Perri C, Csato A, Giordano G, Vuono D and Nagy J B 2010 Synthesis methods of carbon nanotubes and related materials Materials 33092

8. Cao Y, Zhao Y, Li Q and Jiao Q 2009 Catalytic synthesis of nitrogen-doped multi-walled carbon nanotubes using layered double hydroxides as catalyst precursors J. Chem. Sci. 121225

9. Dupuis A C 2005 The catalyst in the CCVD of carbon nanotubes-a review Prog. Mater. Sci. 50929

10. Balasubramanian K and Burghard M 2008 Electrochemically functionalized carbon nanotubes for device applications J. Mater. Chem. 183071

11. Baptista F, Belhout S A, Giordani S and Quinn S J 2015 Recent developments in carbon nanomaterial sensors Chem. Soc. Rev. 444433

12. Zhang X, Shi X and Wang C 2009 Electrodeposition of Pt nanoparticles on carbon nanotubes-modified polyimide materials for electrocatalytic applications Catal. Commun. 10610

13. Tang Z, Ng H Y, Lin J, Wee A T S and Chua D H C 2010 Pt/CNT-based electrodes with high electrochemical activity and stability for proton exchange membrane fuel cells J. Electrochem. Soc. 157245

14. Maiaugree W, Pimanpang S and Towannang M 2012 Co-electrophoretic deposition multiwall carbon nanotubes/Pt counter electrodes for dye-sensitized solar cell Jpn. J. Appl. Phys. 511

15. Scolari M, Mews A, Fu N, Myalitsin A, Assmus T, Balasubramanian K, Burghard M and Kern K 2008 Surface enhanced Raman scattering of carbon nanotubes decorated by individual fluorescent gold particles J. Phys. Chem. C 112391

16. Ye J S, Cui H F, Wen Y, Zhang W D, Xu G Q and Sheu F S 2006 Electrodeposition of platinum nanoparticles on multi-walled carbon nanotubes for electrocatalytic oxidation of methanol Microchim. Acta 152267

17. Lawrence N S, Deo R P and Wang J 2004 Electrochemical determination of hydrogen sulfide at carbon nanotube modified electrodes Anal. Chim. Acta 517131
18. Kubendhiran S, Rajkumar C, Chen S M, Yeah Q J and Thirumalraj B 2018 Charge based electrochemical determination of sulfide ions in water samples using Poly-L-lysine modified electrode J. Electrochem. Soc. 165268

19. Lawrence J, Robinson K L and Lawrence N S 2007 Electrochemical determination of sulfide at various carbon substrates: A comparative study Anal. Sci. 23673

20. Zhang W D, Wen Y, Liu S M, Tjiu W C, Xu G Q and Gan L M 2002 Synthesis of vertically aligned carbon nanotubes on metal deposited quartz plates Carbon 40 1981

21. Lin $\mathrm{C} \mathrm{H}$, Chang $\mathrm{H}$ L, Hsu C M, Lo A Y and Kuo C T 2003 The role of nitrogen in carbon nanotube formation Diamond Relat. Mater. 121851

22. Ye X R, Chen L H, Wang C, Aubuchon J F, Chen I C, Gapin A I, Talbot J B and Jin S 2006 Electrochemical modification of vertically aligned carbon nanotube arrays J. Phys. Chem. B $\mathbf{1 1 0} 12938$

23. Ahmed D S, Haider A J and Mohammad M R 2013 Comparison of functionalization of multi-walled carbon nanotubes treated by oil olive and nitric acid and their characterization Energy Procedia 361111

24. Hooijdonk E V, Bittencourt C, Snyders R and Colomer J F 2013 Functionalization of vertically aligned carbon nanotubes Beilstein J. Nanotechnol. 4129

25. Chu H, Wei L, Cui R, Wang J and Li Y 2010 Carbon nanotubes combined with inorganic nanomaterials: Preparations and applications Coord. Chem. Rev. 254 1117

26. Kharisov B I, Kharissova O V, Ortizmendez U and Gomez I 2015 Decoration of carbon nanotubes with metal nanoparticles: Recent trends Synth. React. Inorg. Met.-Org.; Nano-Met. Chem. 4655

27. Mohajeri S, Dolati A and Daryan S H 2018 The templateassisted electrodeposition of platinum nanowires for catalytic applications J. Electrochem. Sci. Eng. 8205

28. Colbert D T, Zhang J, McClure S M, Nikolaev P, Chen Z, Hafner J H, Owens D W, Kotula P G and Carter C B 1994 Growth and sintering of fullerene nanotubes Science $\mathbf{2 6 6}$ 1218

29. Vielstich W, Lamm A and Gasteiger H A 2003 In Handbook of fuel cells: Fundamentals, technology, applications (New York: John Wiley \& Sons)

30. Tsai M C, Yeh T K, Juang Z Y and Tsai C H 2007 Physical and electrochemical characterization of platinum and platinum-ruthenium treated carbon nanotubes directly grown on carbon cloth Carbon 45383

31. Prabhuram J and Manoharan R 1998 Investigation of methanol oxidation on unsupported platinum electrodes in strong alkali and strong acid J. Power Sources 7454

32. Hughes M N, Centelles M N and Moore K P 2009 Making and working with hydrogen sulfide The chemistry and generation of hydrogen sulfide in vitro and its measurement in vivo: A review Free Radical Biol. Med. 47 1346

33. Kharafi F M A, Saad A Y, Ateya B G and Ghayad I M 2010 Electrochemical oxidation of sulfide ions on platinum electrodes Mod. Appl. Sci. 42

34. Mohajeri S, Dolati A and Ghorbani M 2015 The influence of pulse plating parameters on the electrocodeposition of $\mathrm{Ni}^{-\mathrm{TiO}_{2}}$ nanocomposite single layer and 
multilayer structures on copper substrates Surf. Coat. Technol. 262173

35. Salimi A, Roushani M and Hallaj R 2006 Micromolar determination of sulfur oxoanions and sulfide at a renewable sol-gel carbon ceramic electrode modified with nickel powder Electrochim. Acta 511952

36. Hall J R and Schoenfisch M H 2018 Direct electrochemical sensing of hydrogen sulfide without sulfur poisoning Anal. Chem. 905194

37. Khudaish E A and Hinai A T A 2006 The catalytic activity of vanadium pentoxide film modified electrode on the electrochemical oxidation of hydrogen sulfide in alkaline solutions J. Electroanal. Chem. 587108

38. Shamsipur M, Roushani M, Pourmortazavi S M and Shahabadi N 2014 Amperometric determination of sulfide ion by glassy carbon electrode modified with multiwall carbon nanotubes and copper (II) phenanthroline complex Cent. Eur. J. Chem. 121091

39. Qi P, Wan Y, Zhang D and Wu J 2011 Reduced graphene sheets modified electrodes for electrochemical detection of sulfide Electroanalysis $\mathbf{2 3} 2796$
40. Dilgin Y, Kizilkaya B, Ertek B, Isik F and Dilgin D G 2012 Electrocatalytic oxidation of sulphide using a pencil graphite electrode modified with hematoxylin Sens. Actuators B Chem. 171223

41. Vu D L and Cervenka L 2013 Determination of sulfide by hematoxylin multiwalled carbon nanotubes modified carbon paste electrode Electroanalysis 25 1967

42. Koh A L, Gidcumb E, Zhou O and Sinclair R 2013 Observations of carbon nanotube oxidation in an aberrationcorrected, environmental transmission electron microscope ACS Nano 72566

43. Lim J, Maiti U N, Kim N Y, Narayan R, Lee W J and Choi D S 2016 Dopant-specific unzipping of carbon nanotubes for intact crystalline graphene nanostructures $\mathrm{Nat}$. Commun. 710364

44. Shinde D B, Kushwaha J D A, Aslam M and Pillai V K 2011 Electrochemical unzipping of multiwalled carbon nanotubes for facile synthesis of highquality graphene nanoribbons J. Am. Chem. Soc. 133 4168 